\title{
Genetic reprogramming of human amniotic cells with episomal vectors: Neural rosettes as sentinels in candidate selection for validation assays
}

The promise of genetic reprogramming has prompted initiatives to develop banks of induced pluripotent stem cells (iPSCs) from diverse sources. Sentinel assays for pluripotency could maximize available resources for generating iPSCs. Neural rosettes represent a primitive neural tissue that is unique to differentiating PSCs and commonly used to identify derivative neural/stem progenitors. Here, neural rosettes were used as a sentinel assay for pluripotency in selection of candidates to advance to validation assays. Candidate iPSCs were generated from independent populations of amniotic cells with episomal vectors. Phase imaging of living back up cultures showed neural rosettes in 2 of the 5 candidate populations. Rosettes were immunopositive for the Sox1, Sox2, Pax6 and Pax7 transcription factors that govern neural development in the earliest stage of development and for the IsII/2 and Otx2 transcription factors that are expressed in the dorsal and ventral domains, respectively, of the neural tube in vivo. Dissociation of rosettes produced cultures of differentiation competent neural/stem progenitors that generated immature neurons that were immunopositive for Beta III-tubulin and glia that were immunopositive for GFAP. Subsequent validation assays of selected candidates showed induced expression of endogenous pluripotency genes, epigenetic modification of chromatin and formation of teratomas in immunodeficient mice that contained derivatives of the 3 embryonic germ layers. Validated lines were vector-free and maintained a normal karyotype for more than 60 passages. The credibility of rosette assembly as a sentinel assay for PSCs is supported by coordinate loss of nuclear-localized pluripotency factors Oct4 and Nanog in neural rosettes that emerge spontaneously in cultures of self-renewing validated lines. Taken together, these findings demonstrate value in neural rosettes as sentinels for pluripotency and selection of promising candidates for advance to validation 
assays.

Peer] reviewing PDF | (v2014:07:2457:1:1:NEW 22 Oct 2014) 
2 Patricia G. Wilson, Ph. D., Institute for Regenerative Medicine, Wake Forest School of Medicine, 3 Medical Center Blvd., Winston Salem NC 27157

4 Tiffany Payne, Wake Forest University, 1834 Wake Forest Rd, Winston-Salem, NC 27106 


\section{Introduction}

6 Genetic reprogramming offers unprecedented opportunities for regenerative medicine (Robinton

7 \& Daley 2012; Trounson et al. 2012; Yamanaka 2012). Genetic reprogramming of fetal cells in

8 amniocentesis samples (Ferguson-Smith 2008) is a feasible path to fetus-specific iPSCs for

9 testing the efficacy of pharmaceuticals and for postnatal therapies. From a practical viewpoint,

10 reprogramming of autologous fetal cells for translational use is less likely in the foreseeable

11 future than use of immunologically compatible iPSCs from allogenic sources that have been

12 reprogrammed and manufactured with GMP compliant standards (Turner et al. 2013). From this

13 standpoint, fetal cells in amniotic fluid are attractive because they are among the youngest cells

14 available with minimally invasive procedures.

15 Amniotic cells are unique among targets for genetic reprogramming in that they are drawn from a

16 fluid-filled reservoir rather than a vascularized tissue. Amniocentesis samples contain a mixture

17 of cells that are sloughed from exposed fetal and placental surfaces into amniotic fluid (Maguire

18 et al. 2013; Wilson et al. 2012). Although amniotic cells are most widely known as stromal cells

19 (Murphy \& Atala 2013), fetal skin and placental membranes expose the largest surface area to

20 amniotic fluid (Dobreva et al. 2010) and these epithelia are likely significant contributors of cells

21 to amniocentesis samples (Jezierski et al. 2010). Amniotic fluid is primarily derived by flow from

22 the placenta and fetal lungs into the amniotic sac (Brace 1997) and it is composed mainly of

23 water with some electrolytes and urea from fetal urine (Underwood et al. 2005). A small subset

24 of cells in amniocentesis samples can proliferate in serum-containing media ex vivo; clonal

25 analysis of independent amniocentesis samples indicate that the vast majority of cells do not

26 proliferate (Wilson et al. 2012). Amniotic cell cultures show diversity within and among cell

27 populations (Wilson et al. 2012) that may reflect genetic differences and sampling as well as

28 congenital influences such as placental function, environmental toxins, maternal hormones or

29 simply the length of time that founder cells remained in amniotic fluid before ex vivo culture.

30 The impact of the gestational environment on amniotic cells is not well established and likely to

31 vary among cells, but it is clear that these cells have a finite lifespan in culture and eventually

32 undergo senescence (Wolfrum et al. 2010).

33 Genetic reprogramming can be incomplete and costly in time and resources as a result. Methods

34 to quickly identify promising candidates can reduce this investment and differentiation potential

35 is a logical metric. Neural differentiation of PSCs has been well characterized and is manifest in 
36 living cultures by assembly of neural rosettes (Elkabetz et al. 2008; Liu \& Zhang 2011; Wilson \&

37 Stice 2006; Zhang 2006), radial arrangements of polarized neuroepithelial stem cells, designated 38 here as neural stem/progenitors (NSPs). Rosette assembly and differentiation recapitulates well 39 characterized pathways of neurodevelopment in vivo (Cohen et al. 2013). The transition of PSCs 40 through specification of neuroepithelial stem cells and restriction of cell fate to region-specific 41 subtypes can be traced by spatial and temporal expression of transcription factors that govern 42 neural development in vivo (Elkabetz \& Studer 2008; Wilson \& Stice 2006). Rosette assembly 43 has primarily been used primarily to characterize neural differentiation in established PSC lines

44 (Elkabetz \& Studer 2008; Shin et al. 2006), but it is widely recognized and recently documented 45 that neural rosettes emerge spontaneously in cultures of self-renewing PSCs as (Malchenko et al. 46 2014).

47 Amniotic cells have been reprogrammed with viral vectors, including both integrating (Anchan et 48 al. 2011; Fan et al. 2012; Galende et al. 2010; Ge et al. 2012; Li et al. 2009; Li et al. 2012; Liu et 49 al. 2012; Lu et al. 2011; Wolfrum et al. 2010; Ye et al. 2010) and nonintegrating systems ( $\underline{\text { Jiang et }}$ 50 al. 2014), that efficiently deliver reprogramming transgenes. Leaky or reactivated expression of 51 integrated vector transgenes can hinder differentiation and induce tumors in vivo (Malik \& Rao 52 2013; Mostoslavsky 2012; Rao \& Malik 2012), blocking clinical translation as a result.

53 Nonintegrating vectors circumvent this barrier (Mostoslavsky 2012) and transgene-free iPSCs

54 have been derived from stromal cells in amniotic fluid using a commercial source of 55 nonintegrating Sendai viral vectors (Jiang et al. 2014). Nonintegrating episomal vectors for 56 reprogramming are attractive because they are easily accessible and cheaply amplified with well57 established methods that are used in most research labs (Mostoslavsky 2012). Vectors have 58 improved since their introduction, but reprogramming efficiency of episomal systems remains 59 lower than that of viral systems.

60 Our previous work isolated a collection of independent amniotic cell populations in an effort to 61 define the diversity in amniotic cell populations (Wilson et al. 2012). Donated samples were 62 diluted with serum containing media and directly plated in culture wares without prior 63 centrifugation or refrigeration to minimize loss due to sample manipulation. Some samples were 64 minimally diluted and contained a mixture of stromal and epithelial cell types on the basis of cell 65 morphology. Other samples were similarly isolated except they were highly diluted and plated in 66 multiwell culture wares to generate clonal populations that expanded without paracrine signaling 67 exists in mixed cell populations. An inference of this work (Wilson et al. 2012) and additional 
68 unpublished results is that fewer than 15 founder cells initiate mixed cell populations. Molecular

69 and cytological analysis of mixed cell and clonal populations showed diversity within and among 70 populations, but that stromal and epithelial cells alike shared characteristics of stromal cells, as if

71 epithelial cells exposed to amniotic fluid had initiated epithelial to mesenchymal transition

72 (EMT) before or after entering amniotic fluid. EMT is a process in which epithelial cells acquire 73 stromal cell traits (Nieto 2011). A second inference is that, given that amniotic fluid is exposed 74 principally to epithelial surfaces, is that the bulk of cells in amniotic fluid may be epithelial cells 75 at various stages of EMT.

76 Here we report use of first-generation episomal vectors (Yu et al. 2009) to genetically reprogram 77 independent amniotic cell populations. Given the cost in time and resources required for genetic 78 reprogramming and the uncertainty of reprogramming stromal-like epithelial cells, our strategy 79 was to use assembly of neural rosettes as a sentinel assay to screen and select candidates to 80 advance for validation assays.

81 Materials and Methods

\section{Amniotic cell sources and nomenclature}

83 Amniotic cell populations described herein were derived from amniocentesis samples (Wilson et 84 al. 2012) that were donated with informed consent and a protocol approved by the Institutional 85 Review Board of Wake Forest University Health Sciences (IRB\#00007486). We were blinded to 86 age of the mother, period of gestation or the results of diagnostic tests. Following transfection of 87 target cells and colony isolation, derivative lines were indicated as iChM5 or iChMRC.B1 88 candidates and designated as iPSCs only following successful validation assays. By convention 89 the passages (p) number is indicated as an extension of the population name where relevant. 90 iChM5A and iChM5B populations are referred to collective as iChM5 derivatives for simplicity 91 and likewise, independent candidate lines that were derived from ChMRC.B1 cells are referred to 92 as independent iChMRC.B1 derivatives.

\section{Somatic cell culture}

94 Amniotic cells and HEK293 cells were maintained in DMEM15\% (DMEM supplemented to 15\% 95 fetal bovine serum (FBS), 1\% L-glutamine and 1\% penicillin/streptomycin solution). Cells were 96 routinely maintained on culture wares pretreated with 1:100 dilution of growth factor reduced 
97 matrigel (BD Biosciences). All media components in this work were obtained from Life

98 Technologies unless stated otherwise.

\section{PSC cell culture}

100 The H9 (WA09) line of human embryonic stem cells (hESCs) and iPSC lines were maintained

101 and/or established with a feeder-dependent culture system and standard hESC media

102 supplemented with $1 \%$ penicillin/streptomycin solution on mitomycin-C inactivated mouse

103 embryonic fibroblasts (MEFs) as recommended by the National Stem Cell Bank (NSCB,

104 Madison WI). MEFs were generated from 13-day old CF-1 embryos (Charles River, Inc) and

105 following expansion and mitomycin-C treatment, MEFs were washed extensively with

106 Dulbecco's phosphate buffered saline (DPBS; Life Technologies), harvested with Accutase (Life

107 Technologies) and replated in MEF media on culture wares near $2 \times 10^{5}$ cells $/ \mathrm{cm}^{2}$ for immediate

108 use or cryropreserved with standard methods after $24 \mathrm{hr}$ recovery. Conditioned hESC media was

109 prepared by culture of inactivated MEFs in hESC media without bFGF for $24 \mathrm{hrs}$, supplemented

110 with $4 \mathrm{ng} / \mathrm{ml} \mathrm{bFGF}$ and filtered sterilized before use. Feeder-free cultures were maintained in

111 MEF-conditioned hESC media, mTeSR-1 (StemCell Technologies) or Essential 8 (Life

112 Technologies) media. Passaging of PSCs cultured on MEF feeders or in MEF-conditioned media

113 was done by manual microdissection of optimal undifferentiated colonies with a fire-polished

114 glass pipette using a dissecting microscope. Feeder-free cultures were passaged with EDTA as

115 described (Beers et al. 2012). The ROCK inhibitor Y27632 (Tocris) was routinely added at 5

$116 \mu \mathrm{M} / \mathrm{ml}$ media for $24 \mathrm{~h}$ post-passage.

\section{Genetic reprogramming}

118 The episomal vectors (Addgene, Inc.) that were used in this work are described in Table 1.

119 Episomal vectors were amplified in Top10 bacteria with antibiotic selection in standard Luria

120 Broth and extracted with DNAeasy Kits (Qiagen, Inc) with good recovery of DNA. In each

121 experiment $\sim 8 \times 10^{5}$ target cells were seeded at subconfluent densities $\sim 1.4 \times 10^{3}$ cells $/ \mathrm{cm}^{2}$ and

122 transfected the following day with pooled plasmid combinations in equimolar ratios $(\sim 0.2 \mu \mathrm{g}$

$123 \mathrm{DNA} / \mathrm{cm}^{2}$ ) with Fugene HD (Promega, Corp.) $0.15 \mu \mathrm{l} / \mu \mathrm{g}$ DNA at 8 to $12 \mathrm{hr}$ intervals for a total

124 of 3 transfections. Transfected cells were maintained in DMEM15\% for $\sim 4$ days and then

125 switched to MEF conditioned hESC media supplemented with $2.5 \mathrm{mM}$ valproic acid (Sigma- 
126 Aldrich) for $\sim 2$ weeks after colonies appeared. Independent populations of ChMRC.B1p3 cells

127 were transfected with the 3-vector combination and 7 to 9 colonies were recovered from each

128 population. A single representative colony was selected from each and maintained separately as

129 iChMRC.B1A, iChMRC.B1C, and iChMRC.B1E candidate populations. A population of

130 ChM5p10 cells was transfected with the 2-vector combination, but the population became highly

131 confluent in hESC media within 2 weeks and potential colonies were difficult to identify. The

132 transfected population was passaged with Accutase and replated on MEF feeders. hESC-like

133 colonies emerged within 2 weeks, optimal colonies were pooled and maintained as the iChM5A

134 candidate population. Transfected ChM5p12 cells were maintained for 4 days in growth media,

135 treated with Accutase and passaged to MEF feeders as separate populations; a single hESC-like

136 colony was recovered from one population of transfected cells and maintained as the iChM5B

137 candidate population. Optimal hESC-like candidate colonies and control H9 hESC colonies were

138 passaged as needed to maintain healthy cultures.

\section{Neural differentiation}

140 Following the first manual passage of candidate colonies from MEF feeders, residual colony

141 fragments in the primary culture plate were maintained in conditioned hESC media for 3 to 5

142 days to allow colony expansion and then switched to regular hESC media to encourage

143 spontaneous differentiation as the MEF feeders age and pluripotency of the expanding population

144 by bFGF in hESC media. Rosettes were manually isolated as they emerged and passaged in

$145 \mathrm{hESC}$ media to matrigel-treated cover slips for immunostaining. Long term cultures of neural

146 progenitors/stem cells (NSPs) were established as described (Shin et al. 2006); neural rosettes

147 were serially passaged for 2 or 3 times to enrich for rosettes before dissociation with Accutase

148 and population expansion. Rosette-derived NSP cultures and a commercial source (Millipore)

149 immortalized human midbrain NSPs (hVMNSPs) were maintained in ReNcell NSC Maintenance

150 Media (Millipore) supplemented with $20 \mathrm{ng} / \mathrm{ml} \mathrm{bFGF} \mathrm{and} 20 \mathrm{ng} / \mathrm{ml} \mathrm{EGF}$ or a proliferation media

151 (1:1 mix of DMEM/F-12 and Neurobasal media, 1\% L-glutamine and 1\% penicillin/streptomycin

152 solution, 0.5 X B27, 0.5X N2, $20 \mathrm{ng} / \mathrm{ml} \mathrm{bFGF}$ and $20 \mathrm{ng} / \mathrm{ml}$ EGF) as described (Brace 1997).

153 Differentiation of NSPs was induced by withdrawal of bFGF and EFG from proliferation media.

154 Rosette collections and NSPs were cryropreserved in proliferation media supplemented with $10 \%$

155 DMSO with standard methods. Addition of ROCK inhibitor greatly improved survival at thaw.

156 PCR detection of transgene and vector sequences 
157 Total cellular DNA was isolated with GenePure (Qiagen) or QiaAmp DNA Mini (Qiagen) kits 158 and treated with RNAse to remove RNA. Transgenes or endogenous genes were amplified in 159 reactions containing 100 ng genomic DNA or $<1$ ng plasmid DNA with GC-rich polymerase

160 (Life Technologies) in 1X Buffer A, $3 \mu 1$ of Enhancer and 250nM of oligonucleotide primers

161 (Table 2) with touchdown cycling conditions: 1 cycle $\left[95^{\circ} \mathrm{C}\right.$ for $\left.10 \mathrm{~min}\right], 2$ cycles $\left[95^{\circ} \mathrm{C}\right.$ for 1

$162 \mathrm{~min}, 64^{\circ} \mathrm{C}$ for $1 \mathrm{~min}, 72^{\circ} \mathrm{C}$ for $1 \mathrm{~min}$ ], 2 cycles $\left[95^{\circ} \mathrm{C}\right.$ for $1 \mathrm{~min}, 62^{\circ} \mathrm{C}$ for $1 \mathrm{~min}, 72^{\circ} \mathrm{C}$ for $1 \mathrm{~min}$ ],

1632 cycles $\left[95^{\circ} \mathrm{C}\right.$ for $1 \mathrm{~min}, 60^{\circ} \mathrm{C}$ for $1 \mathrm{~min}, 72^{\circ} \mathrm{C}$ for $1 \mathrm{~min}$ ], 35 cycles $\left[95^{\circ} \mathrm{C}\right.$ for $1 \mathrm{~min}, 58^{\circ} \mathrm{C}$ for

$1641 \mathrm{~min}, 72^{\circ} \mathrm{C}$ for $\left.1 \mathrm{~min}\right]$ and $1 \mathrm{cycle}\left[72^{\circ} \mathrm{C} 10 \mathrm{~min}\right]$.

\section{Transcript analysis}

166 Total cellular RNA was isolated with RNAeasy kits (Qiagen) and contaminating DNA was 167 removed by DNAse treatment. RNA was converted to cDNA using SuperScript First-Strand

168 Synthesis System (Life Technologies) and $1 \mu 1$ of 1:4 dilution of cDNA in water was amplified in 169 each reaction. Transcript levels in Fig. 8A were assayed with QuantiTect Syber Green primer 170 assays (Qiagen) with the exception of cMyc primers (Table 2) with FastStart Universal SYBR

171 Green Master Mix (Roche/Life Technologies). Transcript levels in Fig. 8B were established with

172 TaqMan assays using TaqMan ${ }^{\circledR}$ Gene Expression Master Mix (Life Technologies).

$173 \square$ mplification rates ( $\mathrm{Ct}$ values) of cDNA were assayed in more 2 replicates for each gene. The 174 mean (AVG) and standard error (SE) was calculated with the Descriptive Statistics tool in Excel

175 and normalized to $\beta$-glucuronidase (GUSB) with the $\Delta \Delta \mathrm{Ct}$ method described in Applied

176 Biosystems/Life Technologies technical resources.

\section{Bisulfite sequencing}

178 Genomic DNA was processed with an Epitect kit (Qiagen) as directed by vendor. Amplification 179 products were generated with primers that were specific to converted DNA (Table 2), purified 180 with a Qiaquick PCR purification kit and cloned with a TOPO-TA PCR4 cloning kit (Life 181 Technologies). Plasmid DNA was purified with QIAprep Spin Miniprep kits (Qiagen) or

182 EconoSpin columns (Epoch) and sequenced directly or the vector inserts were first amplified 183 with M13 primers using High Fidelity EcoDry PCR mix (Promega, Corp.) as follows: $95^{\circ} \mathrm{C}$ for $18410 \mathrm{~min}, 40$ cycles $\left(95^{\circ} \mathrm{C}\right.$ for $15 \mathrm{sec}, 54^{\circ} \mathrm{C}$ for $30 \mathrm{sec}$ and $68^{\circ} \mathrm{C}$ for $\left.30 \mathrm{sec}\right), 68^{\circ} \mathrm{C}$ for $10 \mathrm{~min}$.

185 Amplification products were column-purified and sequenced directly (Operon or Genewiz). Data 186 was imported into the SeaView graphical software program for alignment and analysis. The full 
187 set of DNA sequencing files are available here:

188 https://peerj.com/manuscripts/2457/declarations/\#associated.

\section{Imaging and immunocytochemistry}

190 Cells were cultured in multiwell tissue culture plates on cover glass or in multiwall chamber

191 slides that were pretreated with 1:100 dilution of growth factor reduced matrigel. Samples were

192 fixed and immunostained as described (Wilson et al. 2012) with antibodies tabulated in Table 3.

193 Wide-field images were captured with ImagePro software using a QImaging CCD camera

194 mounted on a Leica upright microscope. Immunostaining was repeated in at least 2 technical

195 replicates and in more than 3 independent trials for each marker/combination tested. The images

196 shown throughout this manuscript are representative; our conclusions were based on at least 3

197 fields of view for each replicate and inspection of more than 500 cells for detection of each

198 antigen. Virtually all experiments were done in parallel with positive and negative controls, 199 typically H9 hESCs, parental ChM5 cells or HEK293 as appropriate for the antigen. 


\section{Target amniotic cell populations and nomenclature}

202 Amniotic cell populations were derived from amniocentesis samples (Wilson et al. 2012) that

203 were donated with informed consent and a protocol approved by the Institutional Review Board

204 of Wake Forest University Health Sciences (IRB\#00007486). We were blinded to age of the

205 mother, period of gestation or the results of diagnostic tests. Derivative amniotic cell populations

206 were designated ChM populations, referencing the Christopher Moseley Foundation as the

207 funding source, and a unique identifier. Each mixed cell population was assigned a number and

208 each clonally derived line was assigned an alphanumeric identifier to reflect the amniocentesis

209 sample and the 12-well plate number (if multiple) and an extension (.) that corresponded to the

210 well address of the clone (Wilson et al. 2012). The passage (p) number where relevant is

211 indicated by convention as an extension of the population name ( $\mathrm{p \# )}$.

212 Reprogramming targets were selected to reflect the range of cell types in amniocentesis samples

213 and proliferation characteristics that we considered to be important to the efficiency of

214 reprogramming. The ChM5 mixed cell population was highly enriched for fibroblast-like stromal

215 cells and cell proliferation continues in confluent cultures, generating dense stratified cell layers

216 (Wilson et al. 2012), The ChMRC.B1 clonal population of stromal-like epithelial cells,

217 designated here as epithelial for simplicity, continues to expand in subconfluent cultures, but

218 shows contact inhibition of proliferation in confluent cultures (Wilson et al. 2012), verified by the

219 absence of mitotic figures by immunofluorescence analysis of chromosomes and spindle

220 microtubules (data not shown).

\section{Episomal vector maintenance and Oct4 immunostaining controls}

222 Reprogramming used combinations of 2 or 3 first generation episomal vectors (Table 1) that

223 collectively encoded the four Yamanaka factors Oct4, Sox2, Klf4, cMyc (Takahashi et al. 2007)

224 as well as Nanog, Lin28 and the Large T antigen of SV40 (Yu et al. 2009). Preliminary

225 experiments showed efficient transfection of HEK293 cells with Fugene-HD and correlated

226 maintenance of vector sequences with immunostaining of Oct4 (Fig.1). Transfected HEK293

227 cells were serially passaged; one-third of the population was plated for continued culture, total 
228 DNA was extracted from one-third for polymerase chain reaction (PCR) with published primers

229 (Table 2) and one-third was fixed and immunostained for Oct with a well characterized antibody

230 (Table 3). PCR analysis did not detect the Oct4 transgene in HEK293 cells before transfection

231 and was detected in serial passages 1 through 4 (Fig. 1A), showing that the episomal vectors were

232 present, but unstably maintained in cell populations that were cultured in serum containing

233 media. Primers and antibodies used throughout this work are described in Table 2 and Table 3,

234 respectively.

235 Immunostaining of transfected populations showed a high frequency of Oct4 positive cells

236 following transfection, but the loss of virtually all immunopositive cells by passage 5 (Fig. 1B).

237 Haemacytometer-based counts of Oct4 positive cells showed a decrease from 5\% to $0.5 \%$ over 5

238 the same sequential passages, correlating immunodetection of Oct4 (Fig. 1B) with PCR

239 amplification of the Oct4 transgene (Fig. 1A). Immunostaining of targeted parental populations

240 (Fig. 1C) with the same monoclonal antibody against Oct4 failed to show expression in more

241 than 3 experiments and inspection of more than 500 cells each. We infer from these findings that

242 the targeted parental ChM5 and ChMRC.B1 cell populations did not express the endogenous

243 Oct4 at detectable levels.

244 Recovery and preliminary screen of candidate iPSC colonies

245 The efficiency of chemical transfection of amniotic cell targets was low; less than 5\% of cells

246 were immunopositive for Oct 4 at $48 \mathrm{hrs}$ post-transfection. Subconfluent cultures of $\sim 8 \times 10^{5}$ cells

247 were serially transfected every 8 to 12 hours for 3 transfections in order to increase the number of

248 transfected cells. ChMRC.B1p6 cells were transfected with the 3-vector combination (Table 1) in

2493 separate populations and 7 to 9 candidate colonies were generated in each population. A

250 representative colony from each population was identified by inspection and manually isolated by

251 colony microdissection with a fire-polished pulled glass pipette and expanded independently as

252 the iChMRC.B1A, iChMRC.B1C, and iChMRC.B1E candidate populations. ChM5p10 and

253 ChM5p12 cells were transfected with the 2- and 3-vector combination, respectively (Table 1);

254 multiple colonies were generated by transfection of ChM5p10 cells and a single colony was

255 recovered by transfection of ChM5p12 cells. The ChM5p10 and ChM5p12 derivative candidate

256 lines were designated as iChM5A and iChM5B, respectively. Given the low frequency of

257 transfection and known inefficiency of these first generation episomal vectors (Yu et al. 2009),

258 candidate iChM5A colonies maybe siblings that were derived from the same the founder. We 
259 manually isolated by colony microdissection and pooled candidate iChM5A colonies to conserve 260 resources, reasoning that clonal populations could be established as needed.

261 Optimal colonies growing on feeders were identified by eye and manually recovered by colony 262 microdissection to expand populations. Optimal colonies were defined as those similar to 263 colonies of H9 hESCs (Fig. 2). Colonies of iChM5 derivatives were compact with well-defined 264 edges; colonies of iChMRC.B1 derivatives were similar, but less compact. Cells in candidate 265 colonies were small ( $15 \mu \mathrm{m}$ in diameter) in comparison to the size of parental amniotic cells 266 ( $\sim 50 \mu \mathrm{m}$ to $150 \mu \mathrm{m}$ in diameter), primarily due to apparent reduction in the amount of cytoplasm

267 (Fig. 2). Immunostaining showed nuclear localized Oct4 expression in candidate colonies that 268 was similar to $\mathrm{H} 9 \mathrm{hESCs}$, but colonies included a subset of cells that showed obviously higher

269 levels of Oct4 expression (Fig. 2), possibly reflecting induced expression of the endogenous Oct4 270 gene superimposed with Oct4 transgene expression. Taken together, these observations suggested 271 that candidate colonies did not reflect preexisting Oct4-expressing cells. The frequencies of 272 candidate colonies, 1 to 10 independent candidates from $\sim 8 \times 10^{5}$ transfected cells, was similar to 273 previous studies using these vectors (Yu et al. 2009). Given the low efficiency of chemical 274 transfection, the actual rate of colony formation may have been higher.

\section{Self-assembly and differentiation of neural rosettes in candidate populations}

276 We next screened for evidence of differentiation potential to vet candidate lines for advance to 277 more costly validations assays. Following passage of candidates to fresh feeders, sibling colony

278 fragments were maintained in the original plate as back up cultures, initially maintained in 279 conditioned hESC media for 3 to 5 days to ensure survival of the new culture and then switched 280 to unconditioned hESC media to encourage spontaneous differentiation as feeder layers age.

281 Rosettes did not appear in any of the backup cultures of the 3 independent lines of iChMRC.B1 282 candidates, despite expansion in serial passages. Neural rosettes emerged within $\sim 2$ weeks in 283 back up cultures of iChM5A and iChM5B candidates that were indistinguishable from rosettes in 284 control H9 hESCs (Fig. 3, Supplementary Fig. 1). Rosettes were manually isolated by 285 microdissection as they emerged in sequential backup cultures of iChM5A (p3 and p4) and 286 iChM5B ( 4 4 and p6) and transferred to hESC media on matrigel coated substrates for 287 immunofluorescence analysis or to a proliferation media for cryopreservation. Immunostaining 288 showed nuclear localization of the Sox1, Sox2, Pax6, Pax7transcription factors (Fig. 3, 289 Supplementary Fig. 1) that regulate specification of neuroectoderm in vivo and the Otx2 and 
290 Isl1/2 transcription factors that determine neural subtype identity in the dorsal and ventral

291 domains, respectively, of the neural tube (Elkabetz \& Studer 2008; Hitoshi et al. 2004; Liu \&

292 Zhang 2011; Wilson \& Stice 2006; Zhang 2006). Immunodetection of this collection of

293 transcription factors provided strong evidence for neural identity of rosette structures. Rosettes

294 were immunopositive for the intermediate filament proteins nestin and vimentin (Supplementary

295 Fig. 1) that are commonly used as cytoplasmic markers of neural identity, but these proteins not

296 exclusive to neural derivatives. All of the rosette collections that we tested showed apparent

297 immature neurons with long axonal-like projections that were immunopositive for $\beta$ III-tubulin

298 (Fig. 3, Supplementary Fig. 1). Because rosettes are unique to PSCs, we interpreted these

299 findings as preliminary evidence for pluripotency of iChM5 candidates. Given the absence of

300 rosettes as evidence for differentiation potential, iChMRC.B1 candidates were not pursued

301 further here.

302 Neural rosettes derived from established lines of hESCs and iPSCs are a source of proliferating

303 NSP cultures (Elkabetz \& Studer 2008; Shin et al. 2006). To test whether NSPs could be derived

304 from iChM5 candidates, iChM5A and iChM5B candidates were differentiated toward neural

305 lineages with an established protocol (Shin et al. 2006). Rosettes were manually isolated and

306 enriched by serially passage in a proliferation media and then dissociated to generate monolayer

307 cultures of proliferating NSPs. NSP cultures were generated from both candidates, but we

308 focused on the NSP population that was isolated from iChM5B cultures at passage 6 (NSPB6);

309 this population showed more than $95 \%$ of NSPs were immunopositive for Sox 1 and a few ßIII-

310 tubulin immunopositive immature neurons (Fig. 3). The NSPB6 population shown in Fig. 3 was

311 maintained in culture for more than 30 passages and produced dense mats of immature neurons

312 that were immunopositive for ßIII-tubulin (Fig. 3; Supplementary Fig. 2) by withdrawal of

313 mitogens from proliferation media, inducing differentiation. Apparent glia, cells immunopositive

314 for glia fibrillary acidic protein (GFAP), were infrequent $(<1 \%)$ in all NSP populations, likely

315 reflecting the known delay of gliogenesis relative to neurogenesis (Wilson \& Stice 2006).

316 Although our analysis was not exhaustive, these findings showed derivation of differentiation-

317 competent NSPs and provide added support for pluripotency of iChM5 derivatives and

318 justification for advance to validation assays.

319 Validation of self-renewing, karyotypically normal and pluripotent iChM5 lines 
320 Pluripotency of iChM5 derivatives was tested with conventional validation assays.

321 Immunostaining of iChM5Ap23 and iChM5Bp28 cultures showed expression of Oct4 (Fig. 4A),

322 Sox 2 and Nanog (see below) that was indistinguishable from expression in H9p45 hESCs. We

323 noted that the variability in Oct4 expression that was detected in newly established populations

324 (Fig. 1) was lost with continued culture, consistent with loss of transgene expression and/or up

325 regulation of endogenous Oct4 expression to equivalent levels. Immunostaining showed

326 expression of the Tra-1-81 and SSEA-5 cell surface antigens (Fig. 4A) that are widely used as

327 markers for pluripotency (Tang et al. 2011).

328 The gold standard for pluripotency is the capacity to generate teratomas with specialized cells

329 and tissue derivatives of all three germ layers (Muller et al. 2010). Teratoma assays were used to

330 test the developmental potential of iChM5 derivatives; injection of iChM5Ap14, iChM5Bp14 and

331 control H9p66 hESCs in immunocompromised mice generated teratomas within 9 weeks.

332 Histochemical stains of cryosections showed tissue derivatives of ectoderm, mesoderm and

333 endoderm in tumors derived from iChM5 derivatives and H9 hESCs (Fig. 4B). In consultation

334 with Dr. Mark Willingham, a trained pathologist in the Wake Forest Health Sciences, we

335 identified ectoderm-derived pigmented skin and neural rosettes, secretory tissue typical of

336 endoderm-derived gut, characteristic spheres of cartilage, fat cells, collagen expressing

337 mesoderm derivatives, smooth muscle as well as rare example of striated muscle. Taken

338 together, these findings indicated that both iChM5A and iChM5B derivatives have pluripotent

339 developmental potential to generate tissues and specialized cells from all three germ layers.

340 PSCs can acquire chromosomal abnormalities during culture (Mayshar et al 2010), blocking

341 differentiation in vitro (Wilson et al, 2007; Ben-David, 2014 ) as well as use of PSCs in clinical

342 applications. The genome integrity of iChM5 derivatives was probed with high resolution G-

343 banded karyotype analysis by a commercial service (WiCell Cytogenetics Lab, Madison WI).

344 This assay involves chromosomal incorporation of the intercalating dye ethidiun bromide and

345 induced mitotic arrest with a microtubule poison that disassembles spindles, blocking cell cycle

346 progression (www.wicell.org). Cells are fixed and prepared for digital analysis of chromosomes

347 in mitotic figures and recognition of chromosomal abnormalities with suitable software. The

348 results of karyotype analysis here indicated that early passage iChM5Ap14 and iChM5Bp14 cells

349 had a normal female (46, XX) karyotype without chromosomal abnormalities at a detection limit

350 of $5 \mathrm{Mb}$ (Fig. 4C). A normal karyotype was maintained in late passage iChM5Ap60 and 
351 iChM5Bp60 cells (Fig. 4C), the last passage tested. Prolonged culture of iChM5 derivatives is in

352 contrast to the ChM5 parental cells that senesce near passage 20. Taken together, these findings

353 show that iChM5 derivatives are karyotypically normal and self-renewing iPSCs.

\section{Rosette assembly in validated iChM5 derivatives}

355 Spontaneous differentiation is expected in established PSC cultures and provides evidence for a

356 dynamic state of pluripotency. We next asked whether loss of pluripotency gene expression could

357 be directly associated with spontaneous rosette assembly in validated iChM5 derivatives.

358 Immunofluorescence analysis indicated that the bulk of cells ( $>90 \%)$ in iChM5A and iChM5B

359 cultures ( $\mathrm{n} \geq 3$ of each) expressed Nanog and Sox 2 as well as Oct4. Dual labeling showed that

360 nuclear localized Nanog was correlated with nuclear localized Oct4 (Fig. 5). The absence of

361 nuclear localized Oct4 and Nanog correlated with clusters of more closely apposed cells that

362 were reminiscent of forming neural rosettes. Immunostaining showed all of the cells tested ( $\mathrm{n}>$

363 500), with and without colocalized Oct4 and Nanog expression, expressed Sox2 (Fig. 5),

364 consistent with the known maintenance of Sox2 expression during neural differentiation of PSCs.

365 Dual labeling of Sox 2 and Eg5, a well characterized kinesin that binds to cytoplasmic

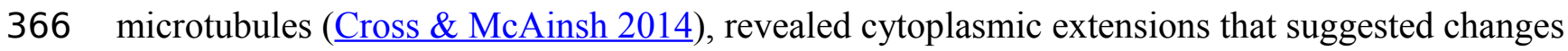

367 in cell morphology during early stages of rosette assembly (Fig. 5). Screens of more than 3 fields

368 of view in at least 3 samples of iChM5A and iChM5B and H9 cells failed to show rosette

369 structures with nuclear co-localization of Oct4 and Nanog. These collective observations

370 correlate coordinate loss of nuclear localized Oct4 and Nanog, but not Sox2, with the early stages

371 of rosette assembly and validate use of rosette assembly as a sentinel for pluripotency of

372 candidate iPSCs as well as neural differentiation potential of established iPSC lines.

373 During the course of these imaging experiments, we noted small equal-sized dots of Nanog

374 immunoreactive signal at a perinuclear position in cells with and without nuclear localized Nanog

375 (Fig. 5). The localization and regularity of these dots suggested immunoreactive signal was due

376 to localization to centrosomes in nonmitotic cells. In an effort to test the dependence of apparent

377 centrosome staining to Nanog expression, we transfected HEK293 cells with the 2-vector

378 combination of episomal vectors (Table 1). Immunostaining showed nuclear localization of

379 Nanog in a subset of cells as expected of transfected populations (Fig. 6), but immunofluorescent

380 signal was detected at centrosomes in virtually all interphase cells, irrespective of nuclear

381 localized Nanog expression. Although the Nanog antibody is a rabbit polyclonal antibody (Table 
382 3) reported to be specific to phosphorlylated forms of Nanog, our results suggest recognition of

383 cross-reactive phosphoepitopes localized at centrosomes. We have since tested for Nanog

384 expression in parental ChM5 cells and other amniotic cell populations with similar results;

385 amniotic cells showed centrosome localized Nanog signal, but neither nuclear localized Nanog

386 nor Oct4 expression was detected, consistent with centrosomal staining that is unrelated to Nanog

387 expression and pluripotency.

\section{Molecular analysis of iChM5 derivatives}

389 Episomal vectors are lost when the vector encoded EBNA-1 gene is epigenetically silenced in 390 PSCs and EBNA-1-dependent replication of episomes is blocked (Frappier 2012; Yates et al. 391 1985). Loss of episomes from iChM5 derivatives was evaluated with PCR, using transgene392 specific primers (Table 2) to probe genomic DNA of iChM5A and iChM5B derivatives at very 393 early (p4-6), mid (p24-25) and late (p59-60) passages and from parental ChM5p10 cells and 394 MEFs. The EBNA-1 and OriP transgenes were detected in early, but not in later passages of 395 candidate iChM5A and iChM5B lines (Fig. 7A), showing loss of episomal vectors during 396 expansion of candidate populations. Detection of EBNA-1 and OriP was correlated with 397 detection of vector transgenes in early passage iChM5p6 cultures, but not in iChM5Ap34 cultures 398 (Fig. 7B). PCR analysis of genomic DNA and transcript analysis of 4 clonal lines derived from 399 iChM5Ap15 indicated that episomes were lost early during culture expansion (data not shown). 400 Taken together, these finding show recovery of vector-free iChM5 derivatives.

401 The results thus far showed expression of Oct4 in iChM5 derivatives, but not in the parental cells.

402 Because demethylation of cytosines in $\mathrm{CpG}$ islands in the promoter of Oct4 is essential for 403 conversion of somatic cells into self-renewing iPSCs and expression of Oct4 (Watanabe et al. 404 2013), methylation of $\mathrm{CpG}$ islands was assayed by bisulfite sequencing of genomic DNA from 405 iChM5Ap18, H9p50 and parental ChM5p10 cells, using previously established primers to 406 amplify Oct4 promoter elements (Freberg et al. 2007). DNA sequence analysis of cloned 407 amplification products (Fig. 7C) showed that $\mathrm{CpG}$ motifs between the distal and proximal 408 enhancers in H9p50 (9\%, 4.0\%) and iChM5Ap18 cells ( $0 \%$, 2\%), respectively, were 409 hypomethylated relative to these motifs in parental ChM5p10 cells (43\%, 31\%). The segment 410 between the proximal enhancer and the transcriptional start site showed methylation in both 411 H9p50 and iChM5Ap18 cells (50\%, 62\%), respectively, that was similar to parental ChM5p10 412 cells (75\%). These observations indicated that genetic reprogramming induced epigenetic 
413 changes in iChM5A derivatives that closely aligned with H9 hESCs. One inference of these

414 findings is that epigenetic silencing underlies the lack of Oct4 expression in parental ChM5 cells

415 and that immunodetection of Oct 4 and other pluripotency genes in iChM5A and iChM5B lines

416 reflects epigenetic modifications of chromatin that allow transcription.

\section{Transcript profiles}

418 Transcription of Oct4 and other genes in the pluripotency network was tested directly by syber

419 green-based quantitative amplification of cDNA (Fig. 8A). Transcripts of Oct4, Sox2, Nanog and

420 Lin28 were not detected above internal controls in cDNA from parental ChM5 cells, but were

421 detected in iChM5A and iChM5B cells and in H9 hESCs. Transcript levels of cMyc were above

422 internal controls in parental ChM5 cells and were similar to levels in iChM5 derivatives and

423 control hESCs although trending lower. Variation in transcript levels was expected given the

424 potential for differentiation within populations, but Sox2 levels were unexpectedly low. The

425 activity of our Sox 2 primers were tested by transcript analysis of cDNA generated from a

426 commercial source of immortalized NSPs derived from human fetal ventral midbrain. The

427 results showed down regulation Oct4 and Nanog, but up regulation of Sox2. Transcript levels in

428 iChM5-derived NSPs were similar, but up regulation of Sox2 was less dramatic (data not shown).

429 These findings indicated that the low Sox2 levels in iChM5 candidates and H9 hESCs did not

430 reflect the Sox 2 primers, but the relative levels of Sox 2 transcripts in these PSC cultures. Taken

431 together, these results confirm transcriptional activation of the pluripotency network in iChM5

432 derivatives.

433 Somatic cell identity is lost or down regulated during genetic reprogramming. Although the

434 somatic source(s) of the parental ChM5 mixed cell pool is unknown and cannot be tested directly,

435 amniotic stromal and epithelial cells alike show stromal cell traits (Wilson et al. 2012). Stromal

436 cell traits of amniotic epithelial cells can reflect epithelial-mesenchymal transition (EMT) in

437 which epithelial cells acquire stromal cell traits by down regulation of E-Cadherin and up

438 regulation of N-Cadherin (Nieto 2011). TaqMan assays were used to probe transcript levels of

439 these cadherins and the EMT inducer TGF $\beta$ in cDNA from parental ChM5 cells, iChM5

440 derivatives, $\mathrm{H} 9 \mathrm{hESCs}$ and bone marrow derived stromal cells (BMMSCs) as a stromal cell

441 control (Fig. 8B). Transcript analysis showed 10 fold lower levels of N-Cadherin and TGF $\beta$ in

442 iChM5 derivatives in comparison to parental ChM5 cells and BMMSCs. E-Cadherin was

443 undetected in parental ChM5 cells and BMMSCs, but a low level was detected in iChM5 
444 derivatives although lower than levels in H9 hESCs. These findings together show loss of 445 stromal cell characteristics by genetic reprogramming of parental ChM5 cells. 


\section{Discussion}

447 The promise of genetic reprogramming has prompted initiatives to develop banks of induced 448 pluripotent stem cells (iPSCs) from diverse sources, in part because immunologically compatible 449 iPSCs from allogenic sources is the more likely path for clinical applications (Turner et al. 2013).

450 Participation of diverse research groups in development of iPSC lines and technologies will

451 benefit from methods that differentiate between pluripotent developmental potential and partially

452 reprogrammed candidates or simply cells expressing pluripotency genes without pluripotent 453 developmental potential. Here, we targeted human amniotic cell populations that we generated 454 in a previous work (Wilson et al, 2012) and report a novel use of neural rosettes as a sentinel for 455 induced pluripotency in candidate iPSC lines and in validated PSC lines.

\section{Self-assembly of neural rosettes as a sentinel for induced pluripotency}

457 Neural rosettes represent a 3-deminisional primitive tissue that approximates the primordial 458 neural tube in vivo (Elkabetz \& Studer 2008; Wilson \& Stice 2006). Spontaneous self-assembly 459 of neural rosettes is unique to PSCs and rosette structures in teratomas are commonly cited as 460 evidence of neural differentiation potential of PSCs. Derivation of neural rosettes has been used

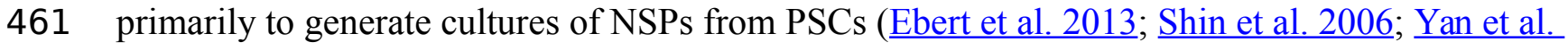

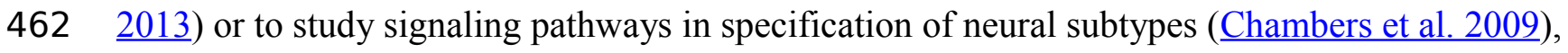
463 but use of rosette assembly has not been reported in the literature as means to screen and select 464 candidates for expansion and validation. Progression through a rosette stage is not essential for 465 directed transdifferentiation of somatic cells into neural derivatives (Ladewig et al. 2013), but 466 self-assembly of neural rosettes is arguably an essential capacity of PSCs and provides a measure 467 of confidence in candidate selection.

468 Rosette assembly has practical value in candidate selection for several reasons. First, rosette 469 assembly can occur by spontaneous differentiation of candidates without application of neural 470 induction protocols. Second, the 3-deminisional structure and organization of rosettes can be 471 readily identified in living cultures by phase imaging and distinguished of from aging MEFs, 472 parental cells and amorphous cell aggregates. Third, spontaneous differentiation of rosettes 473 generates a diverse array of derivative cell types that can be validated by immunostaining of 474 nuclear localized transcription factors (Elkabetz \& Studer 2008; Wilson \& Stice 2006) and use of 475 dual labeling of different transcription factors to enhance the rigor of the assay. This is a key 
476 advantage because nuclear localized transcription factors are superior indicators of neural identity

477 in comparison to more widely used cytoplasmic markers such as nestin and $\beta$ III-tubulin that in

478 our hands are sensitive technical artifacts in fixation and immunostaining. Finally, functional tests

479 are less likely to give false positives in comparison to marker expression alone. Expression of

480 pluripotency markers does not guarantee pluripotency; established hESC lines harboring

481 chromosomal abnormalities can express pluripotency factors, but fail to differentiate (Wilson et

482 al. 2007) and integrated transgenes may not be fully silenced (Malik \& Rao 2013; Mostoslavsky

483 2012; Rao \& Malik 2012) and mistaken for expression of endogenous genes.

\section{Activation and inactivation of the pluripotency network in iChM5A and iChM5B lines}

485 The value of neural rosettes in candidate selection was substantiated by subsequent validation of

486 pluripotency of iChM5 derivatives, including evidence for epigenetic modification of chromatin

487 structure (Fig. 7C) as expected of activation of the endogenous pluripotency network of genes

488 (Fig. 8A,) and down regulation of stromal cell characteristics of parental ChM5 cells (Fig. 8B).

489 Pluripotency is a dynamic state that is difficult to convey in static images, but evidence is critical

490 to discerning differences between expression of pluripotency genes and pluripotent differentiation

491 potential. Here, a dynamic state of pluripotency was evident in spontaneous assembly of neural

492 rosettes in cultures of validated self-renewing iChM5 derivatives; loss of nuclear localized Oct4

493 and Nanog correlated with changes in cell morphology in forming neural rosettes (Fig. 5). This

494 immunofluorescence assay is valuable because it is simple, highly reproducible $(n \geq 6)$ and can

495 provide critical internal controls in the same culture and within the same field of view.

496 Immunostaining in this case is superior to flow cytometry that cannot discriminate between

497 nuclear and cytoplasmic localization of transcription factors or easily correlate gene expression

498 and changes in cell morphology in differentiating cells.

499 Teratoma formation is the accepted standard for pluripotent developmental potential and an assay

500 for the safety of iPSC derivatives in clinical applications (Muller et al. 2010). iChM5A and

501 iChM5B derivatives generated teratomas, under the same conditions and within the same

502 timeframe as control H9 hESCs (Fig. 4B). We used VPA during reprogramming of ChM5 cells;

503 VPA is a small molecule inhibitor of histone deacetyltransferases (HDACs) that is widely used in

504 combination with reprogramming factors in the form of transgenes, mRNA or protein to promote

505 reprogramming (

506 of the cKit cell surface receptor, cultured in conditions for hESCs and transiently exposed to VPA 
507 showed characteristics of pluripotency, including tumor formation in vivo (Moschidou et al.

508 2012). We ascribe induced pluripotency of iChM5 derivatives to genetic reprogramming rather

509 than chemical induction by VPA because newly isolated candidates contained episomal vector

510 sequences (Fig. 7A and Fig. 7B) and because VPA produces global effects on transcription levels

511 that are not known to be heritable.

512 The value of teratomas as assays for pluripotency is under discussion (Buta et al. 2013), in part

513 because evaluation of teratoma composition has a subjective component and standards for

514 assigning tissue derivatives could vary among research groups. We favor use of reliable organoid

515 assays in vitro, such as neural rosettes, to characterize differentiation because such assay and their

516 interpretation is more transparent to researchers and because of the availability of rigorous

517 internal controls. That said, reliable methods to generate organoids from nonneural lineages are

518 only recently beginning to appear in the literature and are not yet broadly used as criteria for

519 differentiation potential.

\section{Differential capacity of iChM5 derivatives for rosette assembly}

521 We show that rosette assembly distinguished iChM5 candidates from iChM5RCB1 candidates.

522 Neural rosettes formed in backup cultures of iChM5A and iChM5B candidates that were

523 comparable to rosettes in H9 controls (Fig. 3, Supplementary Fig.1 and Supplementary Fig. 2).

524 Rosettes were not detected in backup cultures of iChMRC.B1-derived candidates although these

525 candidates were generated by transfection with the same 3 vector combination that produced

526 iChM5B candidates. Similar results were obtained by transfection of the ChM1 population (data

527 not shown) that is highly enriched for epithelial cells (Wilson et al. 2012). The simplest

528 interpretation of these findings is that amniotic stromal cells are easier to reprogram with

529 episomal vectors than epithelial cells and that differences in reprogramming efficiency is

530 reflected in the differential capacity of the candidates to assemble neural rosettes.

531 The underlying cause of differential reprogramming here is uncertain. We show (Fig. 1) that the

532 episomal vectors are unstable in HEK293 cells and we infer that maintenance of all 3 vectors in

533 any one cell is a very low probability event. We are unaware of data reporting selective retention

534 of different episomal vectors, but expression of cMyc on the smallest episomal plasmid in the 3-

535 vector combination (Table 1) could confer some selective advantage in maintenance over the

536 other 2 plasmids. If so, the reduction of Oct 4 copy number would be detrimental to 
537 reprogramming as others show that one copy of an episomal vector encoding Oct4 was

538 insufficient to reprogram fetal fibroblasts (Yu et al, 2009). Vector systems and reprogramming

539 protocols have improved since we initiated this work and further work could show whether the

540 differences in reprogramming reflect reprogramming methods or differences between epithelial

541 and stromal cell types in amniotic fluid or from other sources.

542 Our findings beg the question of whether rosette assembly is a universally valid sentinel of

543 pluripotency. Universality cannot be tested, but several observations are consistent with this

544 expectation. First, rosette assembly reflects differentiation of PSCs to neuroepithelial cells and

545 assembly of cell:cell adhesions and junctions that closely align with assembly of neuroepithelia

546 of the primordial neural tube (Elkabetz \& Studer 2008; Wilson \& Stice 2006). Second, given that

547 differentiation of neuroectoderm is the first germ layer lineage generated during gastrulation of

548 embryos and neural differentiation is an essential benchmark of pluripotency, it is reasonable to

549 expect spontaneous assembly of neuroepithelia in the form of neural rosettes in PSCs.

550 Importantly, assembly of rosettes does not necessarily translate into recovery of PSCs since

551 pluripotency can be lost for a variety of reasons, including differentiation of PSCs in the absence

552 of PSC self-renewal. Third, we show here that rosettes form in synthetic media under feeder free

553 conditions (Fig. 5), indicating that rosette assembly is not media-dependent. Several explanations

554 can be offered for the lack of rosette assembly in candidate lines and other putative PSC lines.

555 First, the candidates, like iChMRC.B1 candidates, are not pluripotent. Second, the

556 candidates/PSCs may harbor chromosomal abnormalities (Wilson et al, 2007), blocking

557 differentiation in spite of Oct4 expression. Third, they form, but they are overlooked and/or not

558 recognized as rosettes. Finally, rosette assembly in PSCs derived from rodent and other species

559 has not been emphasized the literature. It is unclear if this is an oversight, culture conditions

560 using widespread use of passaging with trpsin or for other reasons. Ultimately, the choice to use

561 rosettes as a sentinel is left with the research group. We considered rosette assembly as an

562 essential benchmark of pluripotency that increases rigor in derivations of iPSC lines and expand

563 resources for further research.

\section{Conclusions and repository access}

565 We show recovery of vector-free fully validated iPSCs by genetic reprogramming of cells derived

566 from amniotic fluid with episomal vectors. Spontaneous assembly of neural rosettes provided a

567 sentinel for candidate selection in advance of validation. Coordinated loss of nuclear localized 
568 Oct4 and Nanog in emerging neural rosettes in cultures of self-renewing iPSCs provides a simple

569 and reliable assay for a dynamic state of pluripotency to differentiate pluripotent developmental

570 potential of PSCs from expression of pluripotency genes in somatic cells. Rosette assembly and

571 differentiation is not new to stem cell research, but could maximize resource allocation in

572 derivation and use of PSCs and improve the quality and quantity of iPSCs from diverse sources

573 for clinical applications.

574 The lines generated in this work are available as PGW1i:ChM5A and PGW2i:ChM5B on request

575 from the Rutgers University Cell and DNA Repository, 145 Bevier Road Piscataway NJ 08854-

5768009. 


\section{Acknowledgements}

578 We are grateful to Samantha Jeschonek who generated SMFig.3 while a Summer Scholar at

579 WFIRM. We are grateful to Cynthia Zimmerman, Laddie Crisp, Cathy Mathies, and Raymond

580 Johnson for technical support and insight. We appreciate the thoughtful comments and

581 discussion with members of WFIRM. 
583

584

585

586

587

588

589

590

591

592

593

594

595

596

597

598

599

600

601

602

603

604

605

606

607

608

609

610

611

612

613

614

615

616

617

618

619

620

621

622

623

624

625

626

627

628

629

630

631

632

633

Anchan RM, Quaas P, Gerami-Naini B, Bartake H, Griffin A, Zhou Y, Day D, Eaton JL, George LL, Naber C, Turbe-Doan A, Park PJ, Hornstein MD, and Maas RL. 2011. Amniocytes can serve a dual function as a source of iPS cells and feeder layers. Hum Mol Genet 20:962-974.

Beers J, Gulbranson DR, George N, Siniscalchi LI, Jones J, Thomson JA, and Chen G. 2012. Passaging and colony expansion of human pluripotent stem cells by enzyme-free dissociation in chemically defined culture conditions. Nat Protoc 7:2029-2040.

Ben-David U, and Benvenisty N. 2012. High prevalence of evolutionarily conserved and species-specific genomic aberrations in mouse pluripotent stem cells. Stem Cells 30:612-622.

Brace RA. 1997. Physiology of amniotic fluid volume regulation. Clin Obstet Gynecol 40:280-289.

Buta C, David R, Dressel R, Emgard M, Fuchs C, Gross U, Healy L, Hescheler J, Kolar R, Martin U, Mikkers H, Muller FJ, Schneider RK, Seiler AE, Spielmann H, and Weitzer G. 2013. Reconsidering pluripotency tests: do we still need teratoma assays? Stem Cell Res 11:552-562.

Chambers SM, Fasano CA, Papapetrou EP, Tomishima M, Sadelain M, and Studer L. 2009. Highly efficient neural conversion of human ES and iPS cells by dual inhibition of SMAD signaling. Nat Biotechnol 27:275-280.

Cohen M, Briscoe J, and Blassberg R. 2013. Morphogen interpretation: the transcriptional logic of neural tube patterning. Curr Opin Genet Dev 23:423428.

Cross RA, and McAinsh A. 2014. Prime movers: the mechanochemistry of mitotic kinesins. Nat Rev Mol Cell Biol 15:257-271.

Dobreva MP, Pereira PN, Deprest J, and Zwijsen A. 2010. On the origin of amniotic stem cells: of mice and men. Int J Dev Biol 54:761-777.

Ebert AD, Shelley BC, Hurley AM, Onorati M, Castiglioni V, Patitucci TN, Svendsen SP, Mattis VB, McGivern JV, Schwab AJ, Sareen D, Kim HW, Cattaneo E, and Svendsen CN. 2013. EZ spheres: A stable and expandable culture system for the generation of pre-rosette multipotent stem cells from human ESCs and iPSCs. Stem Cell Res 10:417-427.

Elkabetz Y, Panagiotakos G, Al Shamy G, Socci ND, Tabar V, and Studer L. 2008. Human ES cell-derived neural rosettes reveal a functionally distinct early neural stem cell stage. Genes Dev 22:152-165.

Elkabetz Y, and Studer L. 2008. Human ESC-derived neural rosettes and neural stem cell progression. Cold Spring Harb Symp Quant Biol 73:377-387.

Fan Y, Luo Y, Chen X, Li Q, and Sun X. 2012. Generation of human beta-thalassemia induced pluripotent stem cells from amniotic fluid cells using a single excisable lentiviral stem cell cassette. J Reprod Dev 58:404-409.

Ferguson-Smith MA. 2008. Cytogenetics and the evolution of medical genetics. Genet Med 10:553-559.

Frappier L. 2012. EBNA1 and host factors in Epstein-Barr virus latent DNA replication. Curr Opin Virol 2:733-739.

Freberg CT, Dahl JA, Timoskainen S, and Collas P. 2007. Epigenetic reprogramming of OCT4 and NANOG regulatory regions by embryonal carcinoma cell extract. Mol Biol Cell 18:1543-1553.

Galende E, Karakikes I, Edelmann L, Desnick RJ, Kerenyi T, Khoueiry G, Lafferty J, McGinn JT, Brodman M, Fuster V, Hajjar RJ, and Polgar K. 2010. Amniotic fluid cells are more efficiently reprogrammed to pluripotency than adult cells. Cell Reprogram 12:117-125. 
634

635

636

637

638

639

640

641

642

643

644

645

646

647

648

649

650

651

652

653

654

655

656

657

658

659

660

661

662

663

664

665

666

667

668

669

670

671

672

673

674

675

676

677

678

679

680

681

682

683

684

685

Ge X, Wang IN, Toma I, Sebastiano V, Liu J, Butte MJ, Reijo Pera RA, and Yang PC. 2012. Human amniotic mesenchymal stem cell-derived induced pluripotent stem cells may generate a universal source of cardiac cells. Stem Cells Dev 21:2798-2808.

Hitoshi S, Seaberg RM, Koscik C, Alexson T, Kusunoki S, Kanazawa I, Tsuji S, and van der Kooy D. 2004. Primitive neural stem cells from the mammalian epiblast differentiate to definitive neural stem cells under the control of Notch signaling. Genes Dev 18:1806-1811.

Huangfu D, Maehr R, Guo W, Eijkelenboom A, Snitow M, Chen AE, and Melton DA. 2008. Induction of pluripotent stem cells by defined factors is greatly improved by small-molecule compounds. Nat Biotechnol 26:795-797.

Jezierski A, Gruslin A, Tremblay R, Ly D, Smith C, Turksen K, Sikorska M, and BaniYaghoub M. 2010. Probing stemness and neural commitment in human amniotic fluid cells. Stem Cell Rev 6:199-214.

Jiang G, Di Bernardo J, Maiden MM, Villa-Diaz LG, Mabrouk OS, Krebsbach PH, O'Shea KS, and Kunisaki SM. 2014. Human transgene-free amniotic fluid-derived induced pluripotent stem cells for autologous cell therapy. Stem Cells Dev.

Ladewig J, Koch P, and Brustle O. 2013. Leveling Waddington: the emergence of direct programming and the loss of cell fate hierarchies. Nat Rev Mol Cell Biol 14:225-236.

Li C, Zhou J, Shi G, Ma Y, Yang Y, Gu J, Yu H, Jin S, Wei Z, Chen F, and Jin Y. 2009. Pluripotency can be rapidly and efficiently induced in human amniotic fluidderived cells. Hum Mol Genet 18:4340-4349.

Li Q, Fan Y, Sun X, and Yu Y. 2012. Generation of Induced Pluripotent Stem Cells from Human Amniotic Fluid Cells by Reprogramming with Two Factors in Feeder-free Conditions. J Reprod Dev.

Liu H, and Zhang SC. 2011. Specification of neuronal and glial subtypes from human pluripotent stem cells. Cell Mol Life Sci 68:3995-4008.

Liu T, Zou G, Gao Y, Zhao X, Wang H, Huang Q, Jiang L, Guo L, and Cheng W. 2012. High Efficiency of Reprogramming CD34(+) Cells Derived from Human Amniotic Fluid into Induced Pluripotent Stem Cells with Oct4. Stem Cells Dev 21:2322-2332.

Lu HE, Tsai MS, Yang YC, Yuan CC, Wang TH, Lin XZ, Tseng CP, and Hwang SM. 2011. Selection of alkaline phosphatase-positive induced pluripotent stem cells from human amniotic fluid-derived cells by feeder-free system. Exp Cell Res 317:1895-1903.

Maguire CT, Demarest BL, Hill JT, Palmer JD, Brothman AR, Yost HJ, and Condic ML. 2013. Genome-wide analysis reveals the unique stem cell identity of human amniocytes. PLoS One 8:e53372.

Mayshar Y, Ben-David U, Lavon N, Biancotti JC, Yakir B, Clark AT, Plath K, Lowry WE, and Benvenisty N. 2010. Identification and classification of chromosomal aberrations in human induced pluripotent stem cells. Cell Stem Cell 7:521531.

Malchenko S, Xie J, de Fatima Bonaldo M, Vanin EF, Bhattacharyya BJ, Belmadani A, Xi G, Galat V, Goossens W, Seftor RE, Tomita T, Crispino J, Miller RJ, Bohn MC, Hendrix MJ, and Soares MB. 2014. Onset of rosette formation during spontaneous neural differentiation of hESC and hiPSC colonies. Gene 534:400407.

Malik N, and Rao MS. 2013. A review of the methods for human iPSC derivation. Methods Mol Biol 997:23-33.

Moschidou D, Mukherjee S, Blundell MP, Jones GN, Atala AJ, Thrasher AJ, Fisk NM, De Coppi P, and Guillot PV. 2012. Human Mid-Trimester Amniotic Fluid Stem Cells 
686 Cultured Under Embryonic Stem Cell Conditions with Valproic Acid Acquire Pluripotent Characteristics. Stem Cells Dev.

Mostoslavsky G. 2012. Concise review: The magic act of generating induced pluripotent stem cells: many rabbits in the hat. Stem Cells 30:28-32.

Muller FJ, Goldmann J, Loser P, and Loring JF. 2010. A call to standardize teratoma assays used to define human pluripotent cell lines. Cell Stem Cell 6:412-414.

Murphy SV, and Atala A. 2013. Amniotic fluid and placental membranes: unexpected sources of highly multipotent cells. Semin Reprod Med 31:62-68.

Nieto MA. 2011. The ins and outs of the epithelial to mesenchymal transition in health and disease. Annu Rev Cell Dev Biol 27:347-376.

Rao MS, and Malik N. 2012. Assessing iPSC reprogramming methods for their suitability in translational medicine. J Cell Biochem 113:3061-3068.

Robinton DA, and Daley GQ. 2012. The promise of induced pluripotent stem cells in research and therapy. Nature 481:295-305.

Shin S, Mitalipova M, Noggle S, Tibbitts D, Venable A, Rao R, and Stice SL. 2006. Long-term proliferation of human embryonic stem cell-derived neuroepithelial cells using defined adherent culture conditions. Stem Cells 24:125-138.

Takahashi K, Okita K, Nakagawa M, and Yamanaka S. 2007. Induction of pluripotent stem cells from fibroblast cultures. Nat Protoc 2:3081-3089.

Tang C, Lee AS, Volkmer JP, Sahoo D, Nag D, Mosley AR, Inlay MA, Ardehali R, Chavez SL, Pera RR, Behr B, Wu JC, Weissman IL, and Drukker M. 2011. An antibody against SSEA-5 glycan on human pluripotent stem cells enables removal of teratoma-forming cells. Nat Biotechnol 29:829-834.

Thomson JA, Itskovitz-Eldor J, Shapiro SS, Waknitz MA, Swiergiel J, Marshall VS, and Jones JM. 1998. Embryonic stem cell lines derived from human blastocysts. Science 282:1145-1147.

Trounson A, Shepard KA, and DeWitt ND. 2012. Human disease modeling with induced pluripotent stem cells. Curr Opin Genet Dev 22:509-516.

Turner M, Leslie S, Martin NG, Peschanski M, Rao M, Taylor CJ, Trounson A, Turner D, Yamanaka S, and Wilmut I. 2013. Toward the development of a global induced pluripotent stem cell library. Cell Stem Cell 13:382-384.

Underwood MA, Gilbert WM, and Sherman MP. 2005. Amniotic Fluid: Not Just Fetal Urine Anymore. J Perinatol 25:341-348.

Watanabe A, Yamada Y, and Yamanaka S. 2013. Epigenetic regulation in pluripotent stem cells: a key to breaking the epigenetic barrier. Philos Trans $R$ Soc Lond $B$ Biol Sci 368:20120292.

Wilson PG, Cherry JJ, Schwamberger S, Adams AM, Zhou J, Shin S, and Stice SL. 2007. An SMA project report: neural cell-based assays derived from human embryonic stem cells. Stem Cells Dev 16:1027-1041.

Wilson PG, Devkota L, Payne T, Crisp L, Winter A, and Wang Z. 2012. Clonal populations of amniotic cells by dilution and direct plating: evidence for hidden diversity. Stem Cells Int 2012:485950.

Wilson PG, and Stice SS. 2006. Development and differentiation of neural rosettes derived from human embryonic stem cells. Stem Cell Rev 2:67-77.

Wolfrum K, Wang Y, Prigione A, Sperling K, Lehrach H, and Adjaye J. 2010. The LARGE principle of cellular reprogramming: lost, acquired and retained gene expression in foreskin and amniotic fluid-derived human iPS cells. PLoS One 5:e13703.

Yamanaka S. 2012. Induced pluripotent stem cells: past, present, and future. Cell Stem Cell 10:678-684.

Yan Y, Shin S, Jha BS, Liu Q, Sheng J, Li F, Zhan M, Davis J, Bharti K, Zeng X, Rao M, Malik N, and Vemuri MC. 2013. Efficient and rapid derivation of primitive 
neural stem cells and generation of brain subtype neurons from human pluripotent stem cells. Stem Cells Transl Med 2:862-870.

Yates JL, Warren N, and Sugden B. 1985. Stable replication of plasmids derived from Epstein-Barr virus in various mammalian cells. Nature 313:812-815.

Ye L, Chang JC, Lin C, Qi Z, Yu J, and Kan YW. 2010. Generation of induced pluripotent stem cells using site-specific integration with phage integrase. Proc Natl Acad Sci U S A 107:19467-19472.

Yu J, Hu K, Smuga-Otto K, Tian S, Stewart R, Slukvin, II, and Thomson JA. 2009. Human induced pluripotent stem cells free of vector and transgene sequences. Science 324:797-801.

Zhang SC. 2006. Neural subtype specification from embryonic stem cells. Brain Pathol 16:132-142. 


\section{Table $\mathbf{1}$ (on next page)}

Episomal vectors and vector combinations.

This table described the vectors used in this study, including size of each vector, combinations that were used and structure of the transgene casettes. 
1Table 1. Episomal vectors ${ }^{\mathrm{a}}$ and vector combinations.

\begin{tabular}{lcclll}
\hline Episomal vector $^{\mathrm{b}}$ & $\mathrm{Kb}^{\mathrm{c}}$ combinations $^{\mathrm{d}}$ & ${\text { Cassette }{ }^{\mathrm{e}}}^{\mathrm{C}}$ & Cassette 2 & Casette 3 \\
\hline 3pEP4 E02S CK2M EN2L & 20 & 2 & EF1 $\alpha-\mathrm{O}-2 \mathrm{~A}-\mathrm{S}$ & CMV-K-2A-Mf & EF1 $\alpha-\mathrm{N}-2 \mathrm{~A}-\mathrm{L}$ \\
4pEP4 E02S ET2K & 18 & 2,3 & EF1 $\alpha-O-2 \mathrm{~A}-\mathrm{S}$ & EF1 $\alpha-\mathrm{T}-2 \mathrm{~A}-\mathrm{K}$ & \\
5pEP4 E02S EN2K & 16 & 3 & EF1 $\alpha-O-2 \mathrm{~A}-\mathrm{S}$ & EF1 $\alpha-\mathrm{N}-2 \mathrm{~A}-\mathrm{K}$ & \\
6pCEP4 M2L & 13 & 3 & CMV-M-2A-L & \\
\hline
\end{tabular}

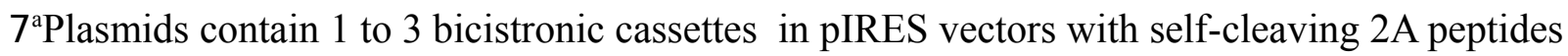

8located between transgenes. Transgene cassettes are expressed under control of the EF1- $\square$ or

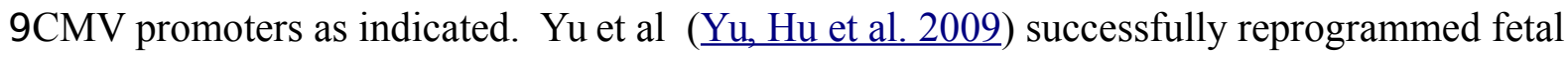
10dermal fibroblasts with 3 combinations (\#) of plasmids: \#4:1,2; \#19:2,5,6; and \#6:2,4,5 as

11designated

$12^{\mathrm{b} R e p r o g r a m m i n g ~ t r a n s g e n e s ~ i n c l u d e ~ O c t 4 ~(O), ~ S o x 2 ~(S), ~ K l f 4 ~(K), ~ c M y c ~(M), ~ L i n 28 ~(L), ~ a n d ~}$ $13 \operatorname{Nanog}(\mathrm{N})$, SV40 Large T antigen (T).

$14^{\mathrm{c}}$ Vector size.

$15^{\mathrm{d}}$ The 2 -vector (2) and 3-vector (3) combinations correspond to combinations \#4 and \#6 ( $\underline{\mathrm{Yu}, \mathrm{Hu}}$ 16et al. 2009).

$17^{\mathrm{e}}$ Bicisitronic casettes in the order in plasmid. 


\section{Figure 1}

Validation of vectors and immunospecificity of Oct4 in control and targeted cells.

(A) PCR analysis. Amplification of the vector-borne Oct4transgene (tgOct4) and endogenous chromosomal Oct4 (eOct4) in nontransfected control HEK293 cells (0) and HEK293 cells transfected with 2-vector combination of the pEP4 E02S CK2M EN2L and pEP4 E02S ET2K plasmids at passages 1 through 5 in serum containing media as indicated. Transfected populations were serially passaged, counted with a haemocytomer at each passage and a portion of each population at each passage was used for DNA isolation, immunostaining and seeding new cultures with defined cell numbers. (B) Immunostaining of Oct4. The first (HEK293:tf+1) and last passage (HEK293:tf +5 ) of transfected cells showed $5 \%$ and $0.5 \%$, respectively, of the cells were immunopositive for Oct4. These findings suggested that episomes were not efficiently replicated and were rapidly lost during expansion of HEK293 populations in DMEM15\% media. (C) Immunostaining of Oct4 in nontransfected targeted populations. Here we show representative fields ofnontransfected ChM5p10 and ChMRB.B1p10 cells that were immunostained for Oct4, using the same monoclonal antibody used in staining HEK293 cells. Repeated independent trials $(n>3)$ failed to show nuclear localized staining. 
A tgOct4 eOct4

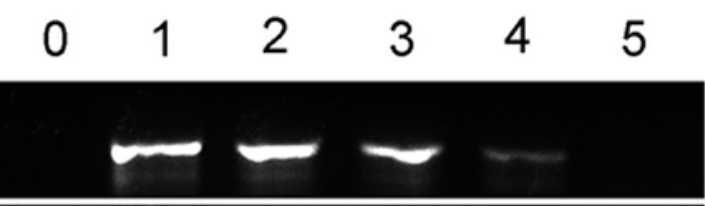

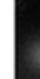

B

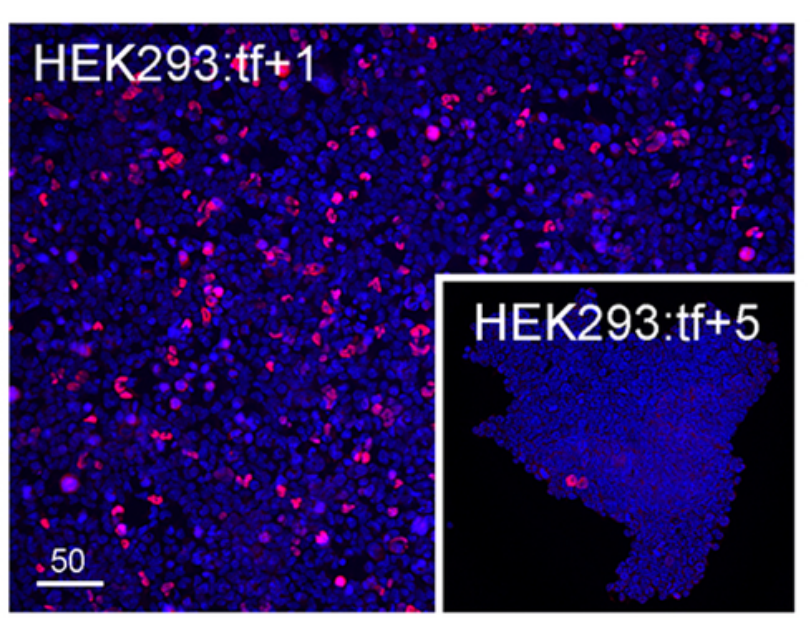

C

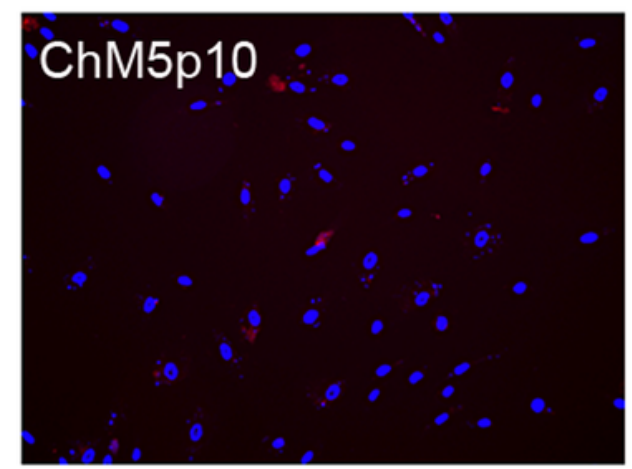

\section{ChMRC.B1p10}

25 


\section{Table 2 (on next page)}

\section{Primers.}

This tables describes all of the primers, other than Qiagen kit contents, that were used in our study. 
1Table 2. Primers $^{\mathrm{a}}$

\begin{tabular}{|c|c|c|c|}
\hline \multicolumn{2}{|c|}{$2 \overline{\mathrm{PCR} / \mathrm{RTPCR}^{\mathrm{b}} \text { size bp }}$} & primer & $5^{\prime}->3^{\prime}$ \\
\hline \multirow{2}{*}{$\begin{array}{l}3 \mathrm{TgOct} 4 \\
4\end{array}$} & \multirow[t]{2}{*}{657} & Oct 4 SF 1 & AGTGAGAGGCAACCTGGAGA \\
\hline & & IRES2SR & AGGAACTGCTTCCTTCACGA \\
\hline \multirow{2}{*}{$\begin{array}{l}5 \text { TgNANOG } \\
6\end{array}$} & \multirow[t]{2}{*}{732} & NanogSF2 & CAGAAGGCCTCAGCACCTAC \\
\hline & & IRES2SR & AGGAACTGCTTCCTTCACGA \\
\hline \multirow{2}{*}{$\begin{array}{l}7 \mathrm{TgSV} 40 \mathrm{LT} \\
8\end{array}$} & \multirow[t]{2}{*}{491} & SV40TSF1 & TGGGGAGAAGAACATGGAAG \\
\hline & & RES2SR & AGGAACTGCTTCCTTCACGA \\
\hline 9TgSox2 & \multirow[t]{2}{*}{534} & IRES $2 \mathrm{SF} 1$ & ACCAGCTCGCAGACCTACAT \\
\hline 10 & & SV40pAR & CCCCCTGAACCTGAAACATA \\
\hline \multirow{2}{*}{$\begin{array}{l}11 \mathrm{TgLIN} 28 \\
12\end{array}$} & \multirow[t]{2}{*}{447} & Lin $28-S F 1$ & AAGCGCAGATCAAAAGGAGA \\
\hline & & SV4 0pAR & CCCCCTGAACCTGAAACATA \\
\hline \multirow{2}{*}{$\begin{array}{l}13 \mathrm{TgKLF} 4 \\
14\end{array}$} & \multirow[t]{2}{*}{401} & KLF 4SF1 & CCCACACAGGTGAGAAACCT \\
\hline & & $\mathrm{SV} 40 \mathrm{pAR}$ & CCCCCTGAACCTGAAACATA \\
\hline \multirow{2}{*}{$\begin{array}{l}15 \mathrm{TgEBNA} 1 \\
16\end{array}$} & \multirow{2}{*}{666} & PEP4SF2 & ATCGTCAAAGCTGCACACAG \\
\hline & & pEP4SR2 & CCCAGGAGTCCCAGTAGTCA \\
\hline \multirow{2}{*}{$\begin{array}{l}17 \text { TgOriP } \\
18\end{array}$} & \multirow{2}{*}{544} & $\mathrm{pEP} 4-\mathrm{SF} 1$ & TTCCACGAGGGTAGTGAACC \\
\hline & & $\mathrm{pEP} 4-\mathrm{SR} 1$ & TCGGGGGTGTTAGAGACAAC \\
\hline \multirow{2}{*}{$\begin{array}{l}19 \text { eOct } 4 \\
20\end{array}$} & \multirow{2}{*}{113} & Oct $4-F 2$ & AGTTTGTGCCAGGGTTTTTG \\
\hline & & Oct4R2 & АСТTCAССТTСССТССААСС \\
\hline \multirow{2}{*}{$\begin{array}{l}21 \text { eGAPDH } \\
22\end{array}$} & \multirow[t]{2}{*}{152} & GAPDHF & GTGGACCTGACCTGCCGTCT \\
\hline & & GAPDHR & GGAGGAGTGGGTGTCGCTGT \\
\hline \multirow{2}{*}{$\begin{array}{l}23 e \mathrm{Myc}^{\mathrm{C}} \\
24\end{array}$} & \multirow[t]{2}{*}{284} & CMYCF & GCCACAGCATACATCCTGTCCGTCCAAGC \\
\hline & & CMYCR & CCAAAGTCCAATTTGAGGCAGTTTAC \\
\hline \multicolumn{4}{|c|}{25 Bisulfite sequencing } \\
\hline \multirow{2}{*}{$\begin{array}{l}2 6 \longdiv { \mathrm { OCT } _ { 4 } { } ^ { 2 } } \\
27\end{array}$} & \multirow[t]{2}{*}{-2609 to -2417} & OCT4_2F & ATTTGTTTTTTGGGTAGTTAAAGGT \\
\hline & & $\mathrm{OCT} 4 \_2 \mathrm{R}$ & 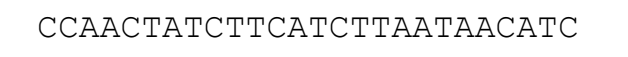 \\
\hline \multirow{4}{*}{$\begin{array}{l}28 \circ \mathrm{CT}_{4}{ }^{4} \\
29 \\
30 \circ \mathrm{OCT} 4 \_6 \\
31\end{array}$} & \multirow[t]{2}{*}{-2136 to -1721} & $\mathrm{OCT} 4-4 \mathrm{~F}$ & GGATGTTATTAAGATGAAGATAGTTGG \\
\hline & & $\mathrm{OCT} 4$ - $4 \mathrm{R}$ & ССТАААСТССССТТСААААТСТАТT \\
\hline & \multirow[t]{2}{*}{-567 to -309} & OCT4_6F & TAGTTGGGATGTGTAGAGTTTGAGA \\
\hline & & OCT6_2R & TAAACCAAAACAATCCTTCTACTCC \\
\hline
\end{tabular}

$32^{\mathrm{a} P r i m e r}$ sequences for PCR [47] and bisulfite sequencing [60].

$33^{\mathrm{b}} \mathrm{Transgene}(\mathrm{Tg})$ and endogenous (e) genes on vectors and chromosomes, respectively.

$34^{\mathrm{c}}$ Primers for RTPCR endogenous cMyc (Kim, Kim et al. 2009). Other transcript profiles used 35EpiTect Assays (Qiagen). 


\section{Table 3 (on next page)}

\section{Antibodies.}

Here we compile a list of the antibodies used in our study, including antigem, host species, monoclonal vs polyclonal, dilution, vendor catalogue number where available. 
1Table 3. Antibodies

\begin{tabular}{lllll}
\hline 2Antigen & host & dilution $^{\text {a }}$ & cat. Number & vendor \\
30ct3/4 & mouse & $1: 300$ & SC-5279 & Santa Cruz \\
4Sox2 & mouse & $1: 200$ & MAB4343 & Chemicon/Milipore \\
5Nanog & rabbit & $1: 500$ & $4903 \mathrm{~S}$ & Cell Signaling \\
6Sox1 & goat & $1: 500$ & SC-17317 & Santa Cruz \\
7Pax6 & mouse & $1: 15$ & PAX6 & DHSB \\
8Pax7 & mouse & $1: 15$ & PAX7 & DHSB \\
90tx2 & goat & $1: 500$ & AF1979 & R\&D Systems \\
10Islet1/2 & mouse & $1: 50$ & $39.3 F 7$ & DHSB \\
11Eg5 & rabbit & $1: 500$ & NB500-181 & Novus Biologicals \\
12nestin & rabbit & $1: 500$ & ab5968 & abCAM \\
13vimentin & goat & $1: 200$ & SC-7557 & Santa Cruz \\
14GFAP & rabbit & $1: 500$ & ab7779 & abCAM \\
15BII-Tubulinmouse & $1: 1000$ & MAB1195 & R\&D Systems \\
16SSEA & mouse & $1: 500$ & ab3355 & abCAM \\
17Tra-1-81 & mouse & $1: 500$ & 560793 & BD Biosciences \\
\hline
\end{tabular}

$18^{\mathrm{a}}$ Monoclonal antibodies were stored in small aliquots at $-80 \mathrm{C}$ and working stocks were

19 maintained undiluted at $4^{\circ} \mathrm{C}$; all other antibodies were maintained in $40 \%$ glycerol at $-20^{\circ} \mathrm{C}$ as 20working stocks or $-80^{\circ} \mathrm{C}$ for long term storage.

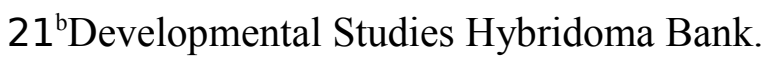




\section{Figure 2}

Characterization of parental cells and candidate colonies

Characterization of parental cells and candidate colonies. Phase images compare the morphology of control H9p54 hESCs with parental ChM5 and ChMRCB1ChMRC.B1 cells. Inserts are magnified $3 X$. Note change in size due to higher area of cytoplasm in somatic cells. Magnification is identical within columns. Immunostaining of H9p45 hESCs and candidate iChM5Ap3 and iChMRCB1ChMRC.B1Ap7 colonies for Oct4 (red) and a fluorescent DNA (blue) dye. Scale bar, 100 microns. 


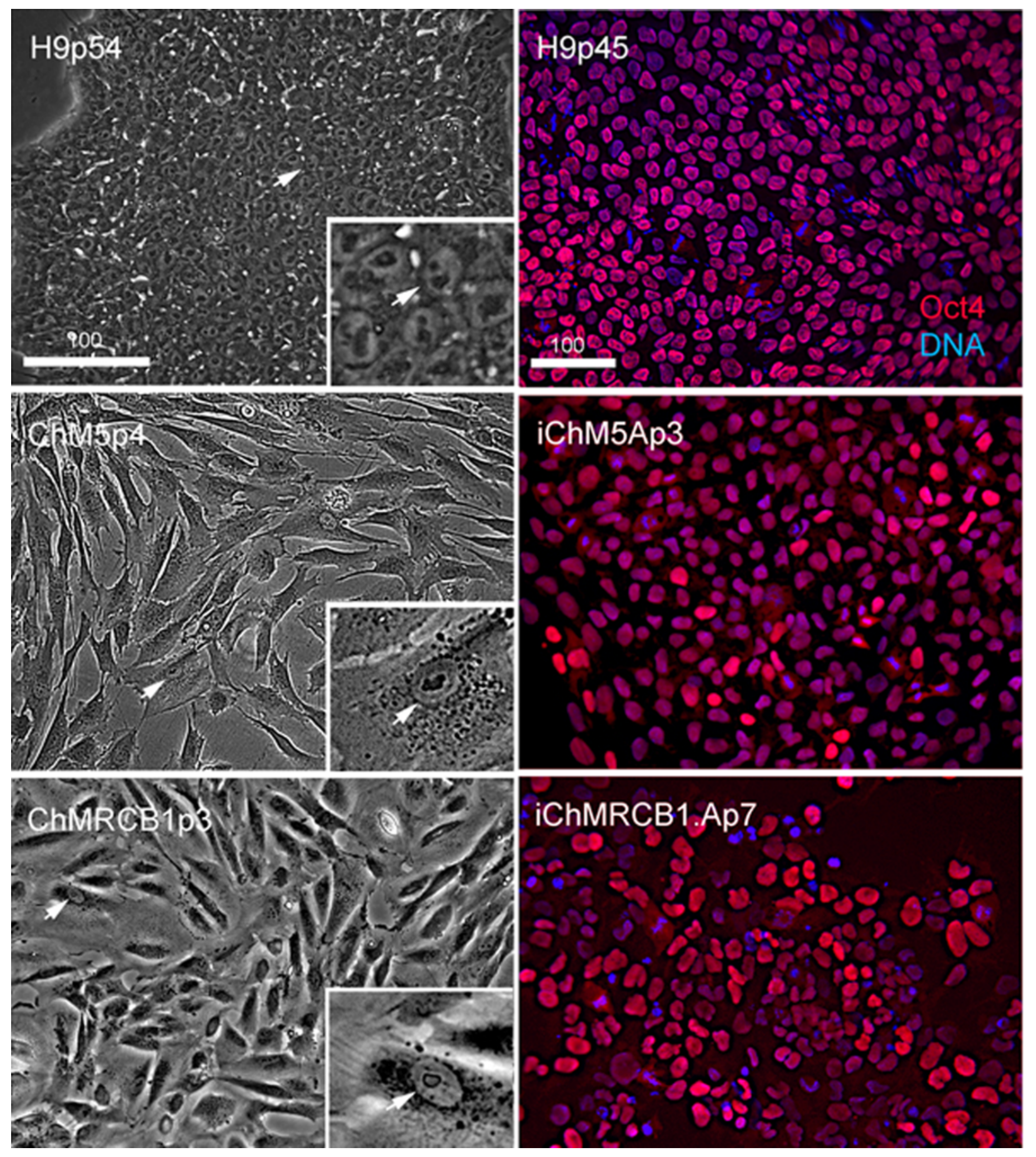




\section{Figure 3}

Neural differentiation potential of candidate iChM5 lines.

The left column shows phase images of neural rosettes (arrows) in living cultures of pluripotent H9 hESCsand candidate iChM5 derivatives (magnification identical; insets show rosettes at $3 \mathrm{X}$ magnification). Color images show immunostaining of rosettes (Rst)and rosette-derived populations of neural/stem progenitors (NSPs). Shown here are NSPs derived from candidate iChM5Bp6 cultures (NSPB6) with neural markers indicated in eachpanel and chromatin stained with a fluorescent dye (blue). The grey scale inset in Rst:H9p47 cells shows immunostaining for blll-tubulin alone to better show the density of immature neurons underlying the rosettes. These results together with immunostaining of iChM5A-derived rosettes and NSPs in Supplementary Figure 1 verify neural identity of rosette structures in backup cultures. Scale bars, in microns. 

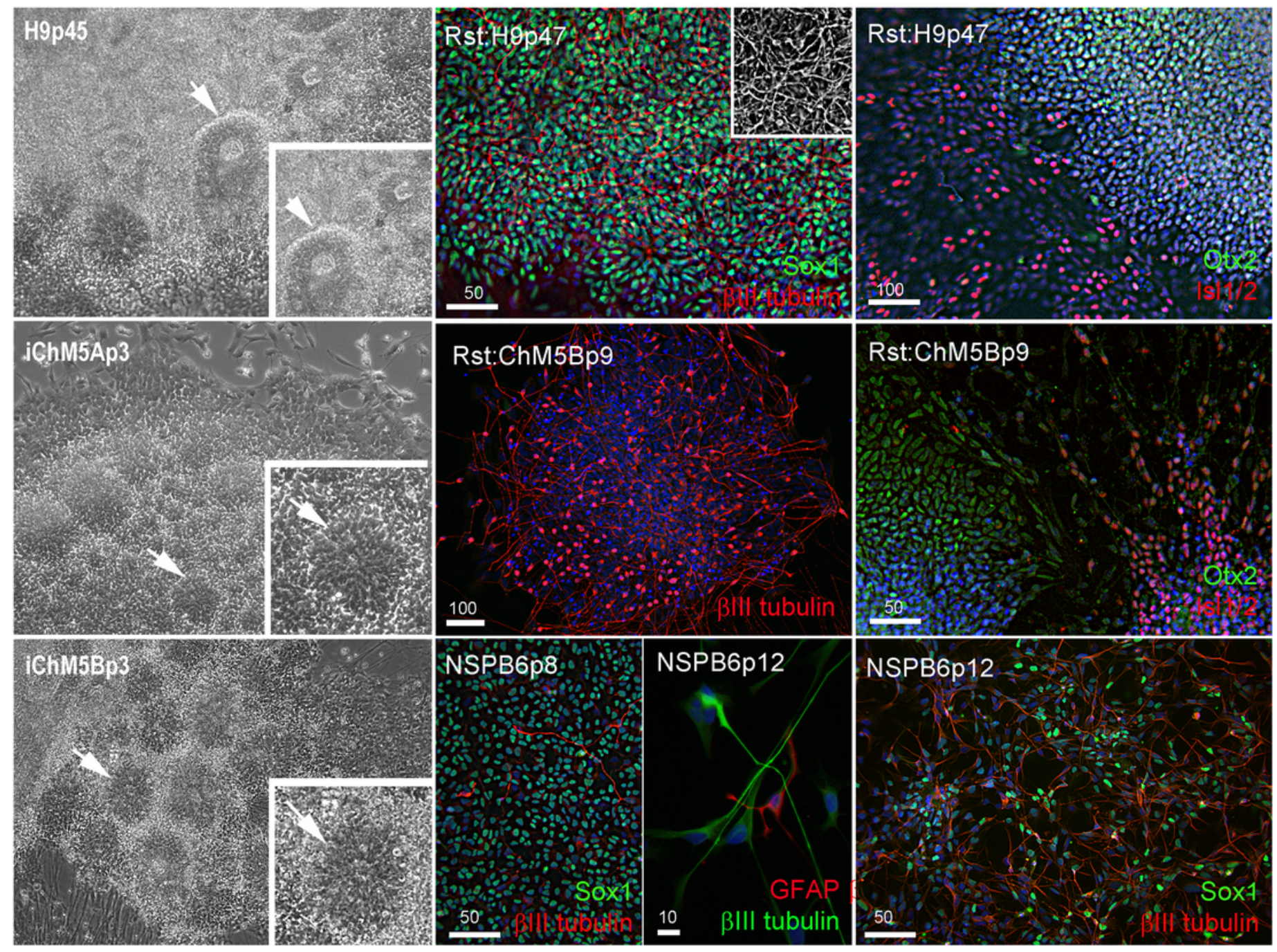


\section{Figure 4}

Validation of pluripotency.

(A) Immunostaining of pluripotency markers. Control H9p45 hESCs, iChM5Ap23 and iChM5Bp28 cells were immunostained as indicated with antibodies against Oct4 and cell surface epitopes Tra-1-81 and SSEA5 that are associated with pluripotency. Note uniform Oct4 signal in iChM5 derivatives in comparison to early passages (Fig. 2). Scale bar, 100 microns. (B) Histochemical stains of teratomas generated with control H9p45 hESCs and iChM5Ap23 and iChM5Bp28 cells. Germ layer derivatives of endoderm (endo), ectoderm (ecto) and mesoderm (meso) in columns with examples of germ layer derivatives indicated by asterisks $(*)$ in each teratoma. Tissue derivatives were identified with the generous help of Dr. Mark Willingham, a pathologist at Wake Forest University Health Sciences. Magnification is identical in all panels. (C) Karyotype analysis of iChM5A and iChM5B cells at early (p14) and late ( $p 60)$ passages showed a normal diploid complement of chromosomes in female cells (XX, 46) without deletions greater than $5 \mathrm{Mb}$, the limits of resolution for this assay. Bar indicates XX chromosme pair. High resolution G-banded karyotype analysis was performed by the Cytogenetics Laboratory of the University of Wisconsin-Madison. 

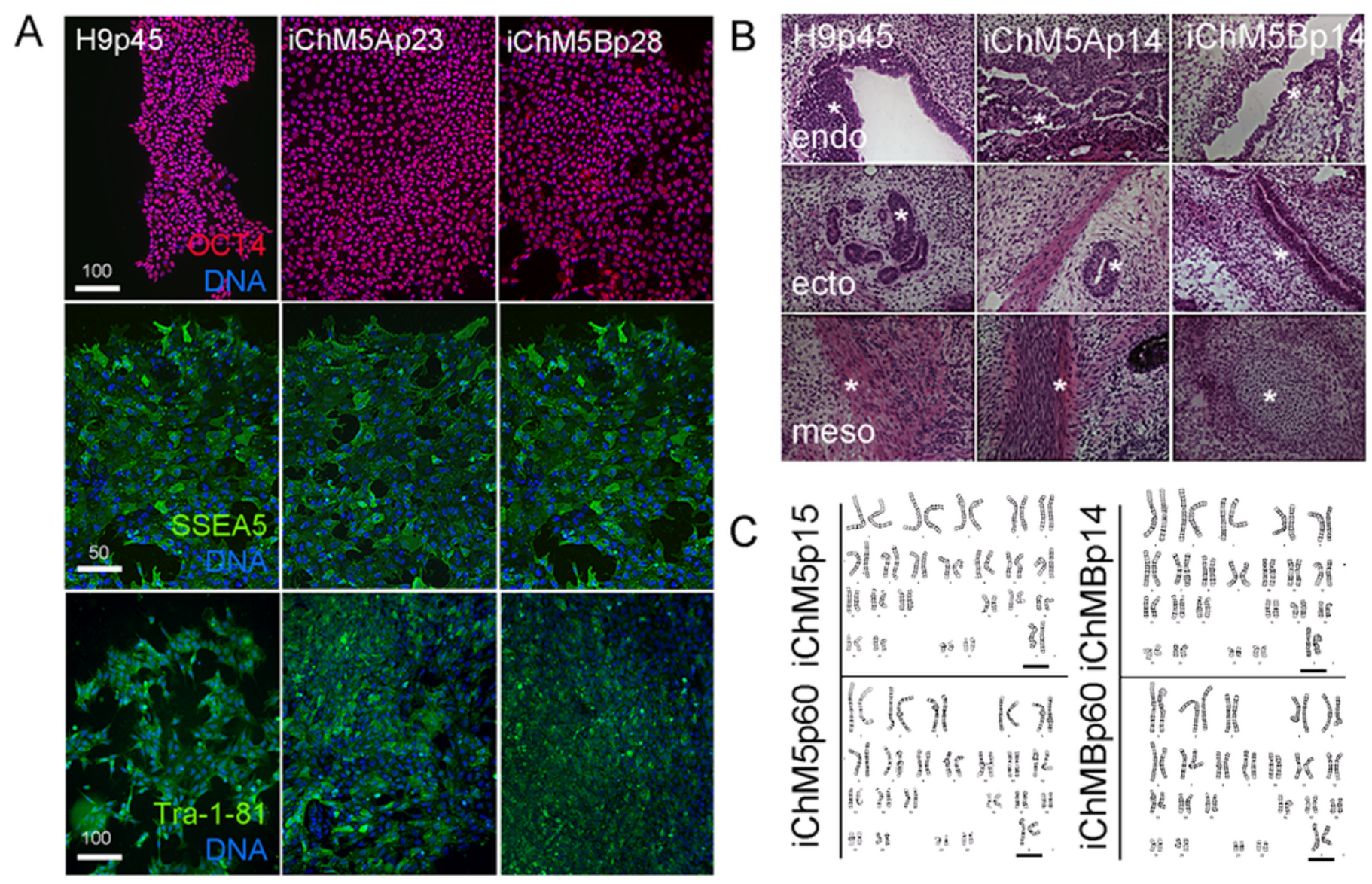

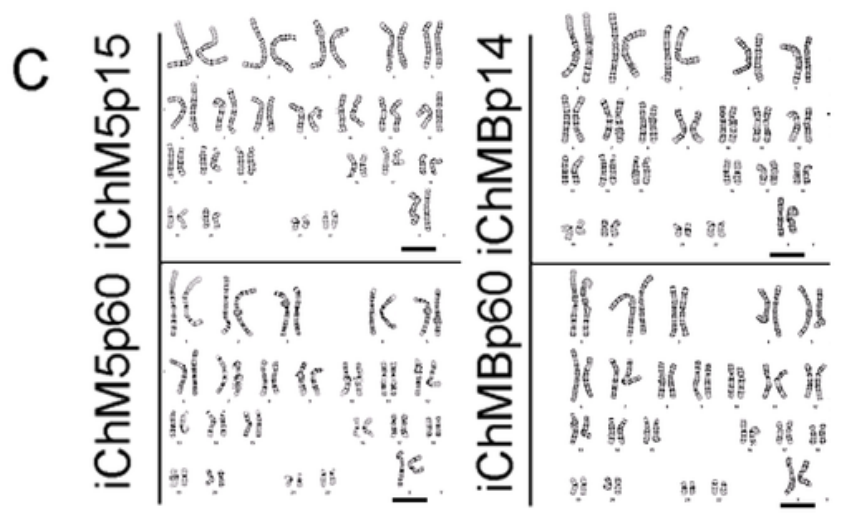




\section{Figure 5}

Spontaneous assembly of rosettes in iChM5 derivatives.

Feeder free cultures iChM5Ap15 and iChM5Bp28 cells in chamber slides were immunostained as indicated. Left panel, emerging rosettes among self-renewing iPSCs; grayscale inset shows 1x magnification of immunostaining of Oct4 alone. Middle panel shows Nanog staining alone with inset at $2 \mathrm{X}$ magnification showing presumptive centrosomes (arrows). Bottom left panel shows forming rosettes immunopositive for Sox2 and Eg5. Bottom right panel shows low magnification image of immunostaining of Sox 2 in this iChM5Ap15 culture, showing that virtually all cells were immunopositive. Grey scale inset shows representative forming rosette. Asterisks $(*)$ in each panel indicates example of forming rosette.Scale bar, 50 microns. 
iChM5Ap15\%
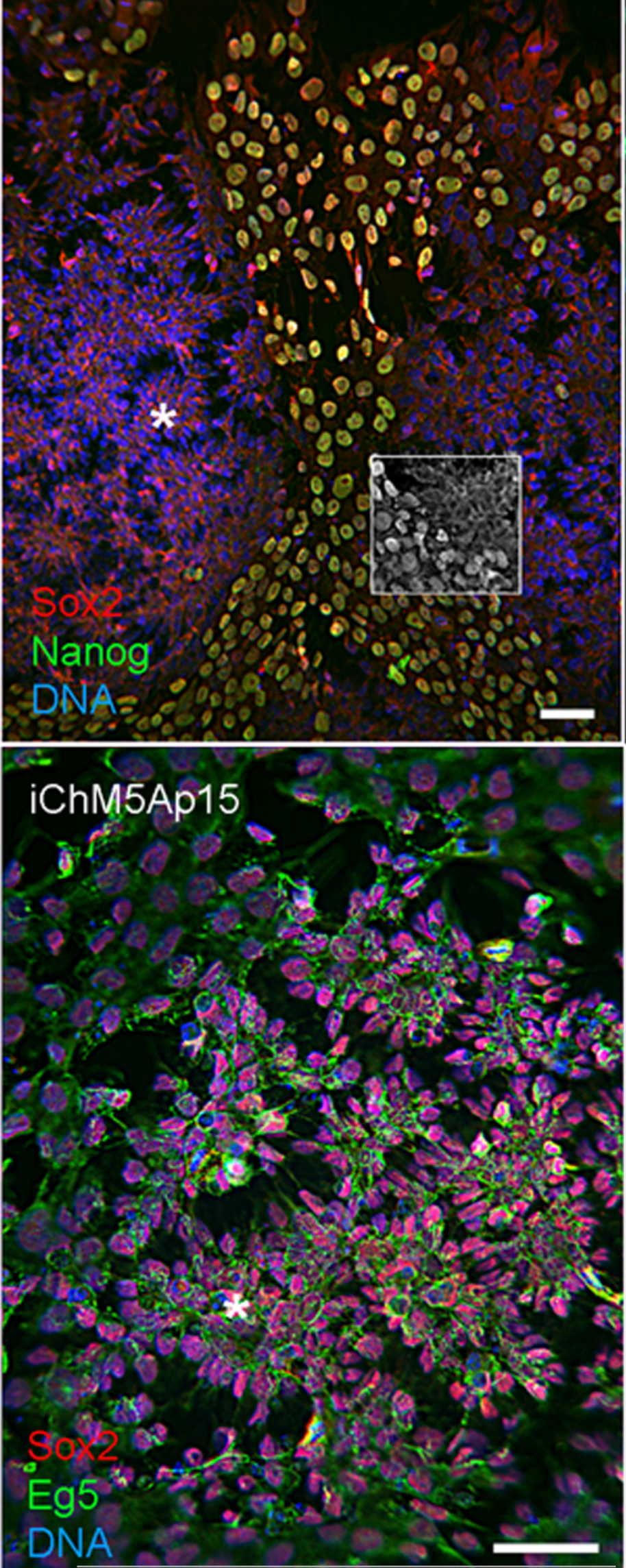

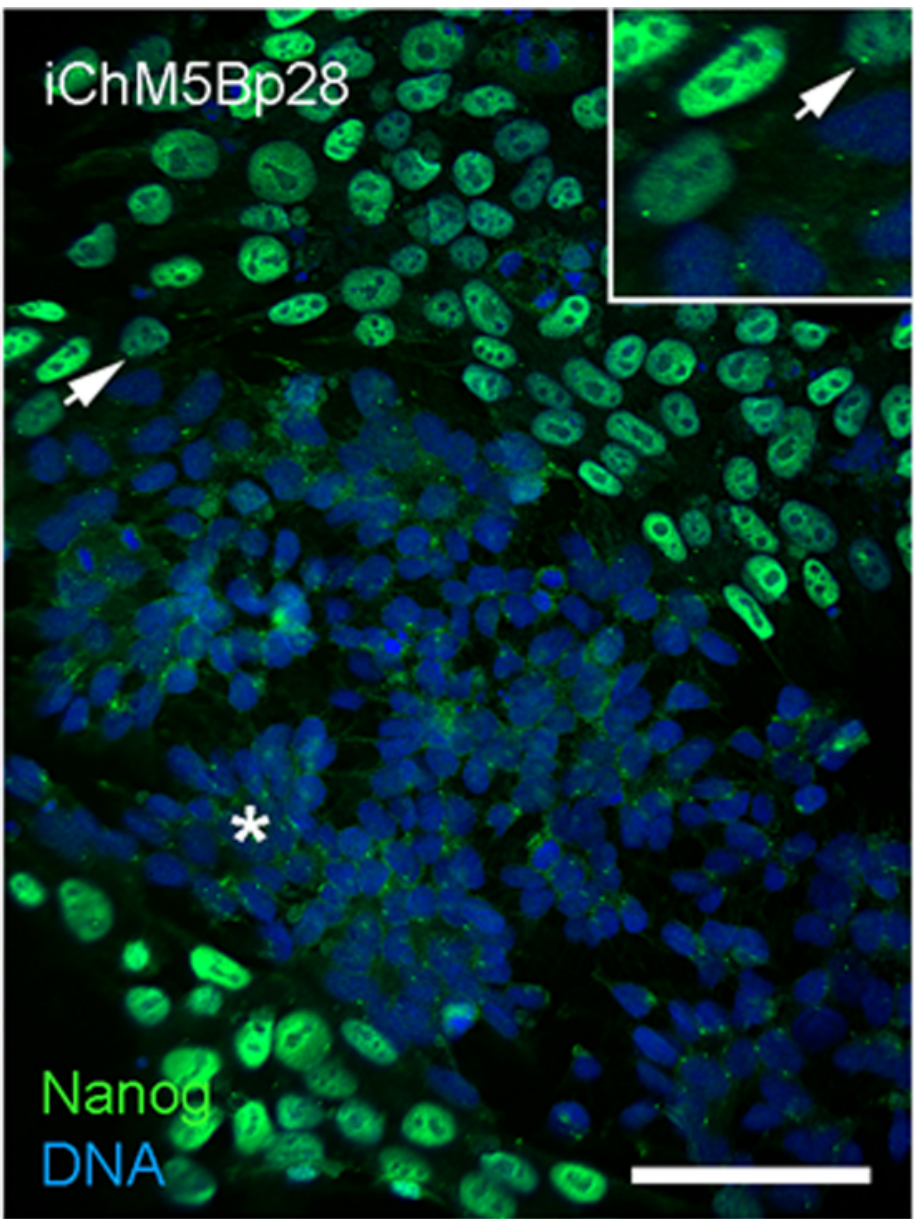

iChM5Ap15

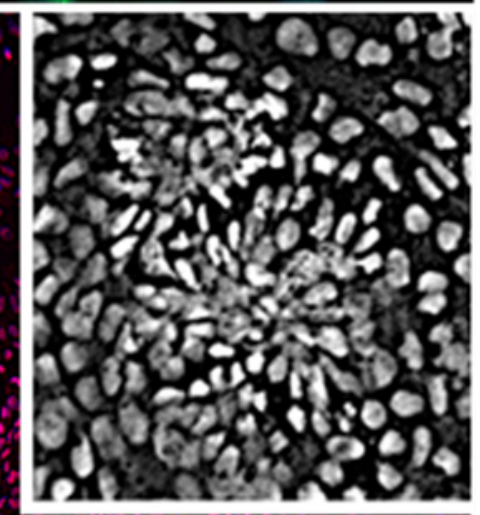




\section{Figure 6}

Nanog signal at centrosomes in nontransfected HEK293 cells.

Image shows HEK293 cells transfected with 2-vector combination of pEP4 E02S CK2M EN2L and PEP4 E02S ET2K plasmids and stained with antibodies against Oct4 and Nanog and a fluorescent chromatin dye as indicated. Grayscale inset at $2 X$ magnification shows Nanog signal at presumptive centrosomes (arrow) that are within focal plane of the objective. Centrosomes that are out of the focal plane are not visible here. Differential staining for Oct4 (red), Nanog (green) or Oct4 and Nanog (yellow) expression reflects the presence of Oct4 on both vectors and Nanog on one vector. Scale bar, 50 microns. This image shows that immunostaining of Nanog at centrosomes is likely independnet of Nanog expression because cells lacking Nanog localization show immunostaining of centrosomes. 
PeerJ Reviewing Manuscript

HEK293:tf

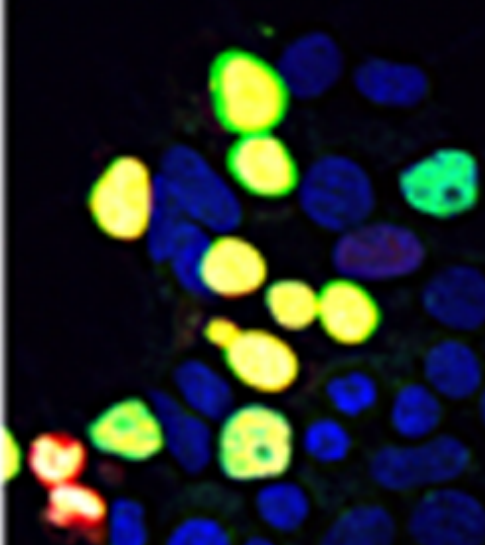

4
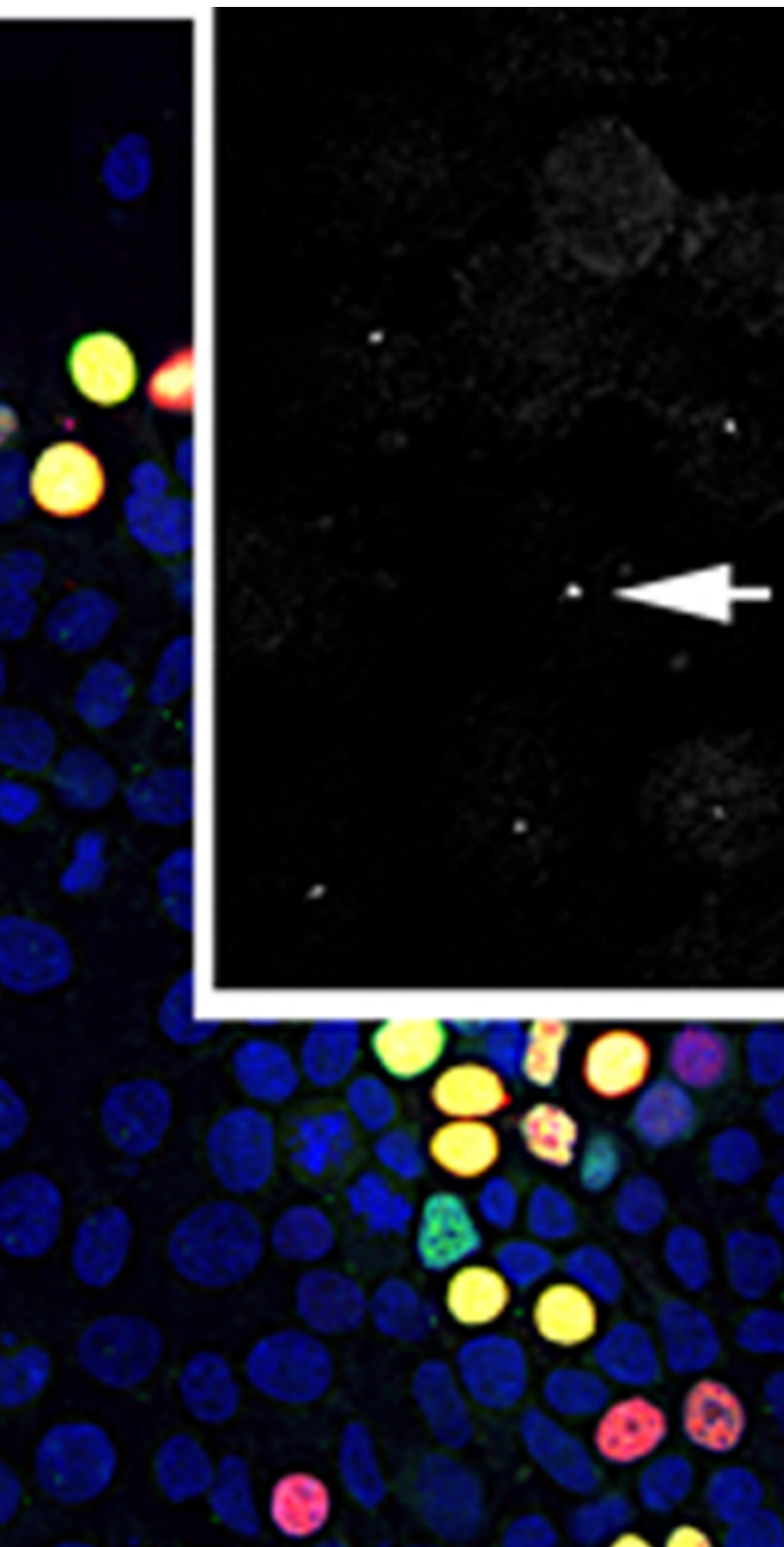

0

\section{0

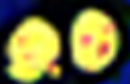

Oct4

c

Nanog

0

DNA 


\section{Figure 7}

Molecular analysis of iChM5 and iChM5B lines.

(A) Amplification of vector sequences. Genomic DNA was probed for the vector transgenes

(tg) OriP and EBNA-1 and for endogenous (e) GAPDH and Oct4 genes as controls. Note that the eOct4 band is near the gel edge. (B) Amplification of transgenes. Genomic DNA from iChM5Ap34 and iChM5Ap6 cells was probed for the vector transgenes Oct4, Nanog, SV40 Tantigen, Sox2, Lin28, Klf4 and the endogenous copy of Oct4. The upper and lower range of ladder markers are indicated. Data in (A) and (B) show that vectors are lost from iChM5 derivatives during population expansion. (C). Bisulfite sequence analysis of methylation of Oct4 promoters elements. Diagram shows the Oct4 promoter containing a distal enhancer $(\mathrm{DE})$, proximal enhancer $(\mathrm{PE})$, proximal promoter element $(\mathrm{PP})$ and transcription start site $($ TSS +1$)$. Open and closed circles represent unmethylated and methylated cytosines, respectively, at the positions indicated as inferred from DNA sequence analysis of cloned fragments. Each row of circles represents the cytosines in $\mathrm{CpG}$ motifs from a single cloned fragment. The percentage of methylated cytosines in each clone set is indicated. These results show that methylation of the parental cells was modied during reprogramming and became similar to that of control H9 hESCs. 

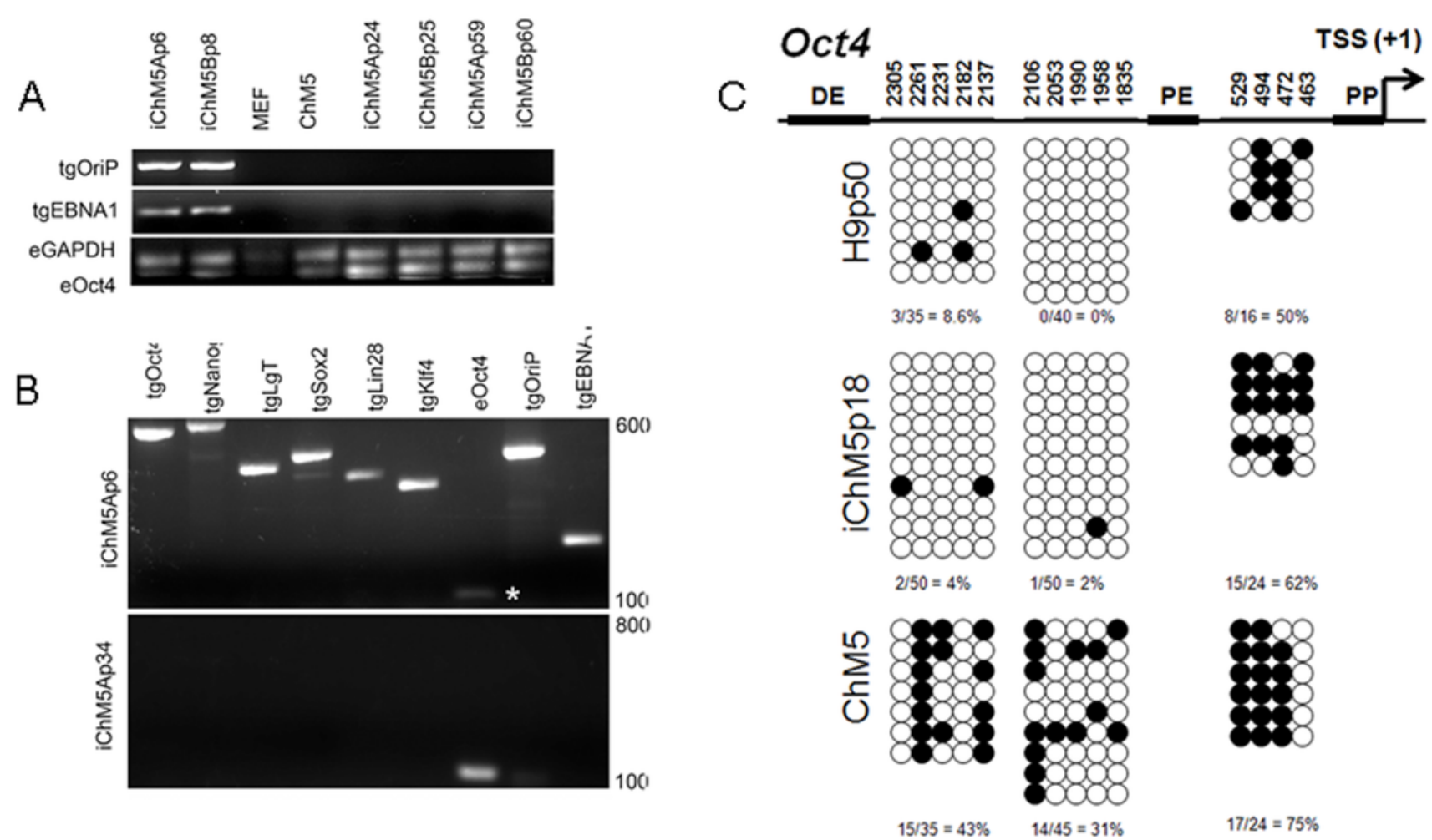


\section{Figure 8}

Transcript profiles

(A) Transcript profiles of pluripotency factors. ddCt values for ChM5p10, H9p44, iChM5Ap18, iChM5Bp20 cells and immortalized human ventral midbrain neural progenitors (hVMNSPs) were normalized to levels of b-glucuronidase (GUSB). cMyc levels in single experiment indicated with asterisks (*) or not determined (n.d.). (B) Transcript profiles of EMT-associated genes. ddCt values for H9p44, iChM5Ap15, iChM5Bp37, ChM5Ap10, BMMSCp5 were probed for GUSB, E-Cadherin (ECAD), N-Cadherin (NCAD) and TGFb with TaqMan gene expression assays and presented as fold expression as normalized to GUSB. 
A

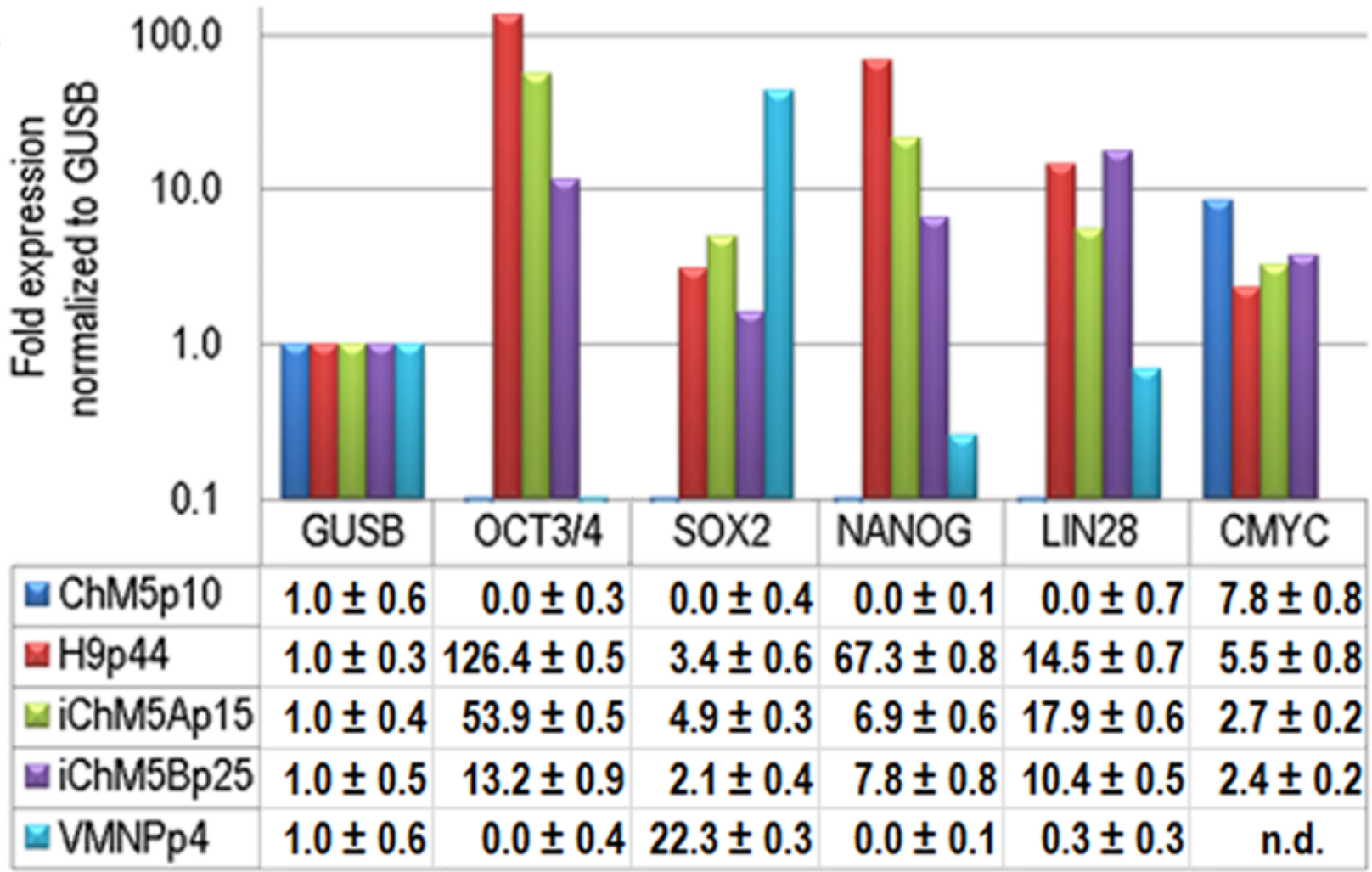

B

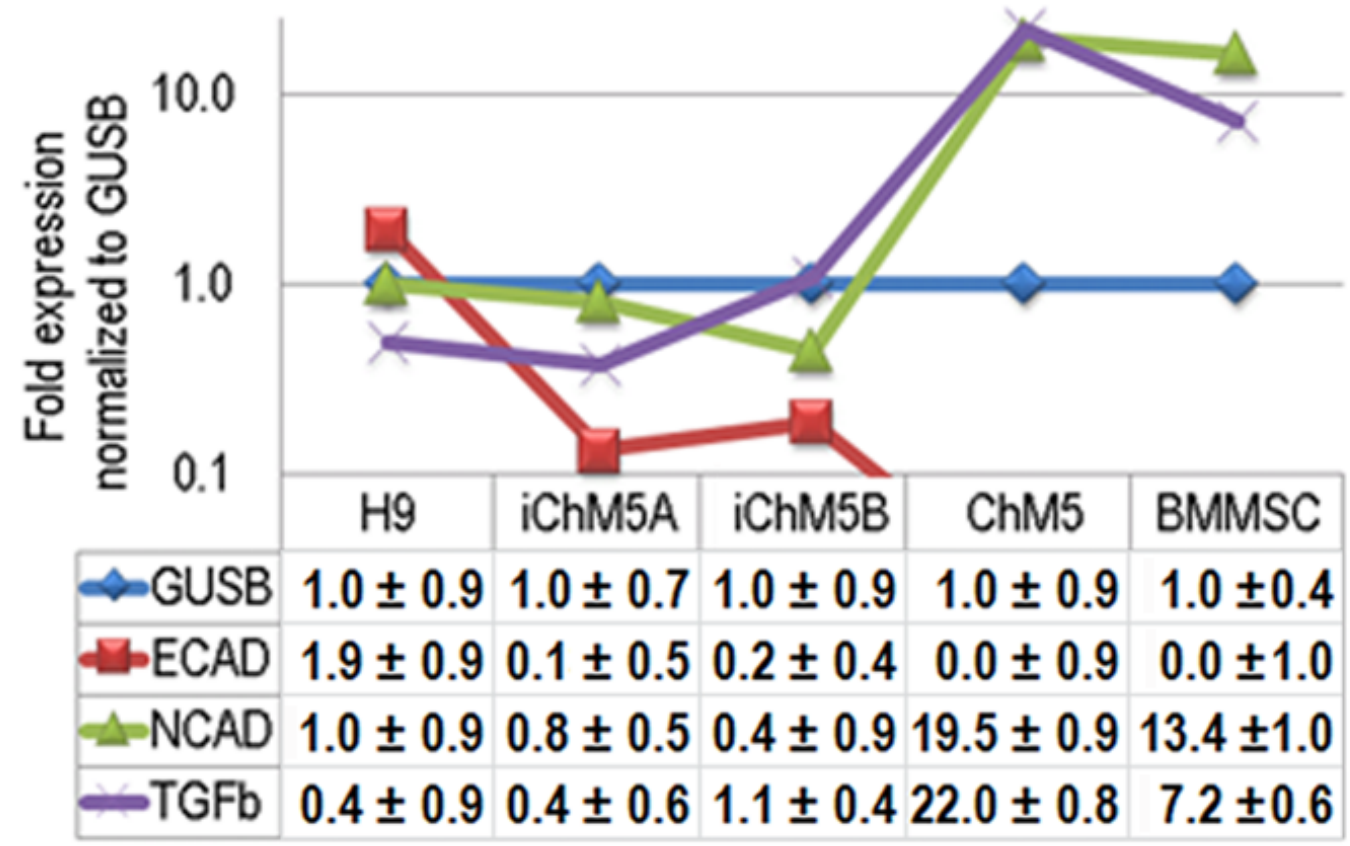

